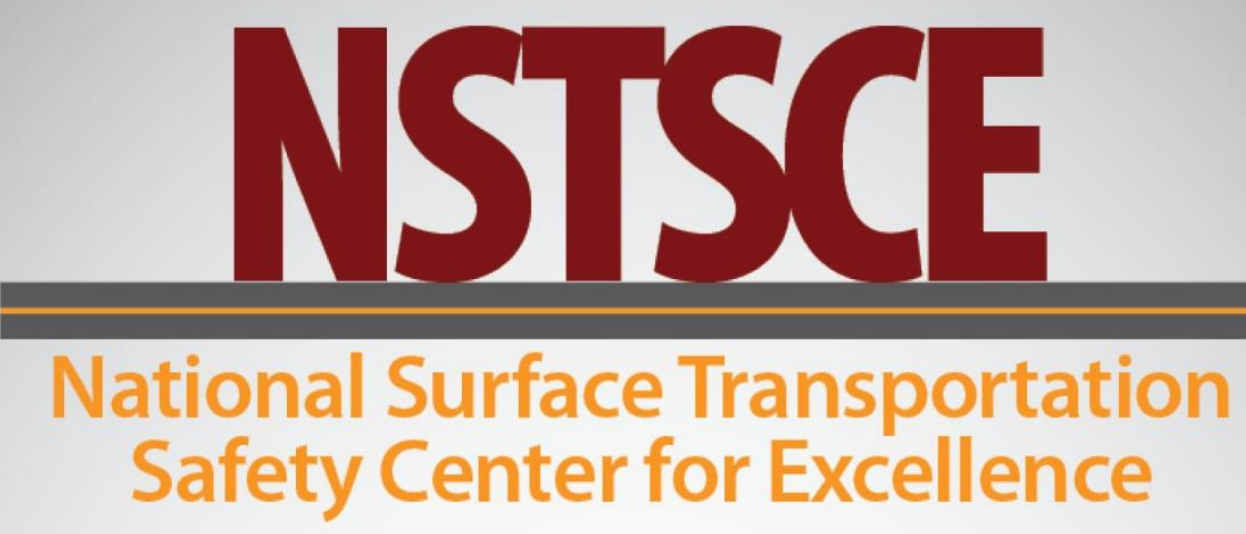

\title{
Case Study on Worksite Health and Wellness Program for Commercial Motor Vehicle Drivers
}

J. Erin Mabry • Jeffrey Hickman • Richard Hanowski

Submitted: October 9, 2013

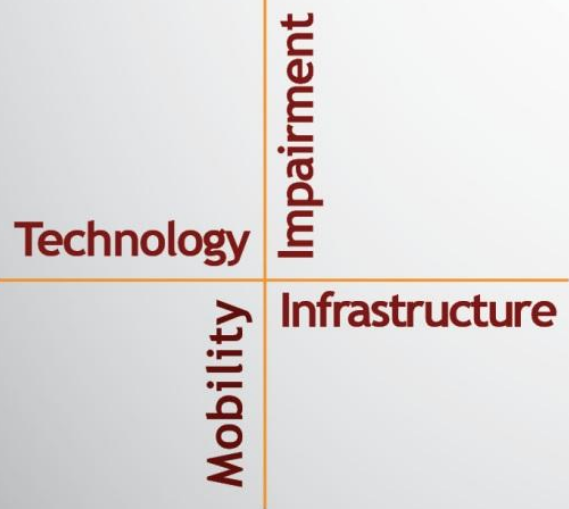




\section{ACKNOWLEDGMENTS}

The authors of this report would like to acknowledge the support of the stakeholders of the National Surface Transportation Safety Center for Excellence (NSTSCE): Tom Dingus from the Virginia Tech Transportation Institute, John Capp from General Motors Corporation, Lincoln Cobb from the Federal Highway Administration, Chris Hayes from Travelers Insurance, Martin Walker from the Federal Motor Carrier Safety Administration, and Cathy McGhee from the Virginia Department of Transportation and the Virginia Center for Transportation Innovation and Research.

The NSTSCE stakeholders have jointly funded this research for the purpose of developing and disseminating advanced transportation safety techniques and innovations.

The Government and others acting on its behalf shall have unlimited rights to obtain, reproduce, publish or otherwise use the data developed in the performance of this cooperative agreement pursuant to 49 CFR Part 19.36. 


\section{EXECUTIVE SUMMARY}

\section{Overview}

Due to the elevated prevalence of overweight and obesity in the transportation industry and the risks that accompany obesity, a health and wellness $(\mathrm{H} \& \mathrm{~W})$ program at a leading trucking organization was initiated to reduce obesity and the associated risks. In 2008 Schneider National Inc. (SNI), along with United Healthcare (UHC) and Atlas Ergonomics, launched a companywide, voluntary H\&W Program with their employees. Atlas is a leading ergonomic service and technology provider for healthcare, office, and transportation environments. Since the H\&W Program launched in 2008, UHC and Atlas have worked with SNI to offer health and wellness programs, ergonomic and injury prevention services, on-site physical therapy and health screens, and overall wellness coaching to approximately 17,000 company-insured employees, including commercial drivers, at twelve SNI operating centers across the U.S. and Canada. Employee spouses are also eligible to enroll in the H\&W Program. The purpose of this Case Study is to detail SNI's H\&W Program with Atlas Ergonomics and UHC and to evaluate the opinions, perceptions, and program satisfaction of participating drivers and program staff. The findings from this Case Study will aid in the development of recommendations for a carrier-implemented $\mathrm{H} \& \mathrm{~W}$ program.

\section{Procedures}

Virginia Tech Transportation Institute (VTTI) research personnel conducted phone interviews with key SNI, Atlas, and UHC personnel to examine and detail the H\&W Program. A total of six people from the aforementioned organizations participated in three phone interviews. Personnel from SNI, Atlas, and UHC also provided the VTTI research personnel with documents and materials, including program protocols, preliminary results, and presentations to help the research team detail the $\mathrm{H} \& \mathrm{~W}$ program. Online questionnaires were administered to participating Atlas and UHC staff, as well as SNI drivers, to inquire about their opinions, perceptions, and satisfaction with the H\&W Program. A total of 94 drivers and 27 staff questionnaires were completed.

\section{Program Outcomes}

The following summary discusses key program outcomes highlighted by drivers and program staff involved in SNI's H\&W Program.

\section{Driver Summary}

The majority of drivers were satisfied with SNI's H\&W Program as they reported improved health since participating in the program and would recommend the program to other drivers.

- Program Likes

- The insurance incentive and health concerns were the primary reasons cited by drivers for participating in SNI's H\&W Program.

- Drivers appreciated SNI's concern about their health and felt encouraged and supported in their efforts to be proactive regarding their health. 
○ Drivers stated that the Atlas and UHC health coaches are accessible, helpful, provide good advice, are easy to understand, and help them reach realistic goals that improve their health.

- Drivers felt their participation in the program made them more aware of their health and lifestyle choices and provided them with the tools to take a proactive approach to improving their health.

- Drivers liked the exercise aspect of the H\&W Program.

- Suggestions for Improvement

- Drivers recommended that additional Atlas on-site clinics within the network of SNI terminals would better serve the needs of the participants.

- Drivers expressed concern that their private health information would be "leaked" to their employer or that negative health results would be used against them; thus, they wanted more anonymity within the program.

- Drivers requested additional access to health coaches and more active monitoring and assistance from coaches, including exercise monitoring and coaching.

- Drivers wanted more opportunities to exercise, including equipping additional operating centers with exercise equipment.

\section{Staff Summary}

The majority of staff were satisfied with the H\&W Program and reported many program likes, as well as suggestions for program improvement.

- Program Likes

- Staff felt the education program provided drivers was adequate.

○ Staff felt the health testing and assessments were adequate and had few suggestions for improvement.

- Having full-time physical and occupational therapy available for drivers and offering a variety of health programs that target specific health needs at no cost to company-insured drivers are key benefits of the H\&W Program. On-site therapists and facilities at SNI operating centers, as well as flexible scheduling for assessments and coaching, make it convenient for drivers to participate.

- Staff agreed that discussing assessment results with participants face-to-face and individualized coaching work well for developing a trusting relationship between coach and driver.

- Working with participants to make small, manageable lifestyle changes and providing them with the tools they need for success are important. 
- Staff recognized that the drivers often struggle with staying on track with their exercise and nutritional goals due to their mobile lifestyle and irregular work schedules; therefore, helping them to adopt healthy habits wherever and whenever they can is important.

- Staff felt that the incentive program worked well for encouraging participation in the H\&W Program.

- Suggestions for Improvement

- Staff agreed that increasing the number of on-site Atlas clinics within the SNI network of terminals would be beneficial.

- Staff felt that driver participation in the program could be increased by marketing and communicating the program and its benefits.

- Staff suggested providing more information about the H\&W Program and services during driver training and orientation.

- Staff reported that carrier management could benefit from education regarding the program to better assist and understand their participating drivers and that health coaches could benefit from additional training on working with over-the-road drivers who are away from home for extended periods of time.

- Staff stressed the importance of easing drivers' minds that their participation in the program will not jeopardize their jobs if their health is considered poor. Staff felt that addressing this issue would increase driver participation substantially.

- Staff suggested offering additional interim incentives as small goals are met and successes achieved. 



\section{TABLE OF CONTENTS}

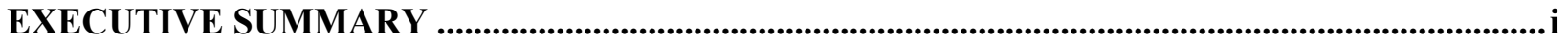

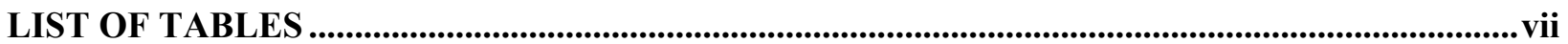

LIST OF ABBREVIATIONS AND SYMBOLS .......................................................................................ix

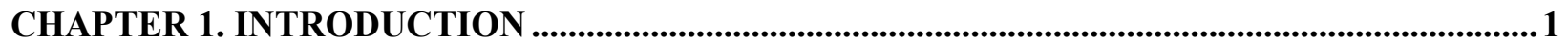

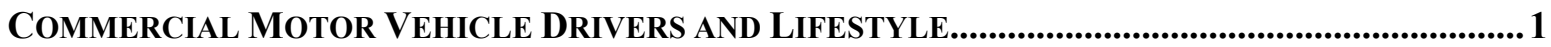

COMMERCIAL MOTOR VEHICLE DRIVERS AND HEALTH RISKS...............................................1

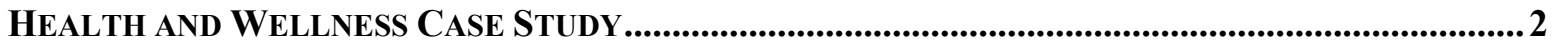

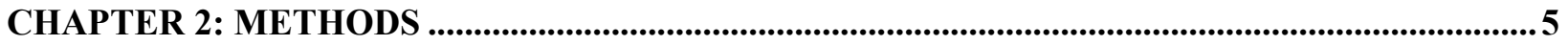

CHAPTER 3: HEALTH \& WELLNESS PROGRAM DESCRIPTION............................................... 7

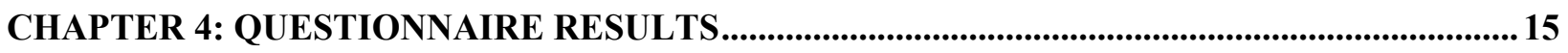

CHAPTER 5: SUMMARY …....................................................................................................................35

SUMMARY OF DRIVER OPINIONS AND PERCEPTIONS......................................................................35

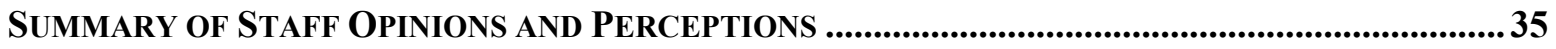

APPENDIX A: PHONE INTERVIEW SCRIPT AND PROCEDURES .........................................43

APPENDIX B: DRIVER AND STAFF QUESTIONNAIRES ............................................................... 47

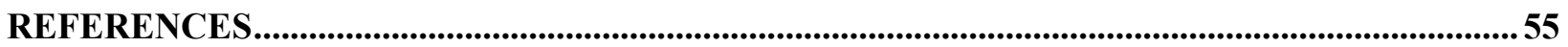





\section{LIST OF TABLES}

Table 1. Questionnaire participant demographic information........................................... 16 



\section{LIST OF ABBREVIATIONS AND SYMBOLS}

BMI Body mass index

CMV Commercial motor vehicle

CVD Cardiovascular disease

DOT Department of Transportation

FMCSA Federal Motor Carrier Safety Administration

HOS Hours of Service

H\&W Health and Wellness

$\mathrm{OC}$

Operating Centers

SNI

Schneider National, Inc.

UHC

United Healthcare

VTTI

Virginia Tech Transportation Institute 


\section{CHAPTER 1. INTRODUCTION}

Given the distributed operations in long-haul trucking, limited access to healthy food options, and sedentary lifestyle, it is not surprising that the prevalence of obesity among commercial motor vehicle (CMV) drivers far outpaces that of the U.S. adult population. Approximately twothirds of the U.S. adult population is overweight or obese, and nearly one third of U.S. adults may be considered obese [1]. Studies in the U.S. have reported overweight and obesity rates in CMV drivers to be as high as 56 to 85 percent $[2,3]$. Obesity is a primary risk factor for many chronic conditions, including heart disease, type 2 diabetes, sleep disorders, several types of cancer, and osteoarthritis. Furthermore, work performance and healthcare costs are affected by overweight and obesity [4]. Obesity has been associated with workplace absenteeism [5, 6], and obese workers may be less productive than non-obese workers [7]; in CMV drivers, obesity is associated with greater risk of crashes [8]. Overweight workers have also been shown to have higher healthcare costs than their normal-weight counterparts, primarily due to higher incidence of chronic disease and longer, more difficult, and expensive recovery time from illness or injury [9]. Worksite interventions are ideal for CMV drivers due to the nature of the industry (i.e., long work hours and extended time spent at carrier terminals).

\section{Commercial Motor Vehicle Drivers and Lifestyle}

The typical lifestyle of a CMV driver may include irregular work and sleep hours, physical inactivity, poor eating habits and nutrition, and mental and physical stress. Since the update to the hours of service (HOS) regulations in 2005, a long-haul driver may spend up to 11 hours driving and 14 hours on-duty per day and up to 70 total driving hours in an 8-day period [10]. CMV drivers typically work irregular schedules and must frequently invert their sleep-wake cycle (e.g., sleeping during the day and remaining awake at night). Their day-to-night work schedule can also change frequently, depending on work demand. In order to cope with these schedule demands, CMV drivers may be unable to obtain enough sleep and suffer partial sleep deprivation [11]. Long hours spent driving and inadequate sleep can limit motivation and opportunities for exercise, in addition to encouraging unhealthy eating habits. Drivers may spend the majority of their day in their truck cab and sleeper berth, further constraining their daily physical activity. To maximize their federally restricted driving hours, CMV drivers may snack all day to keep their energy up and consume one large meal at the end of their shift. This group is also restricted to eating at the restaurants they are able to access while making their revenueproducing deliveries, which primarily include truck stop diners and fast food restaurants. The limited cab space inside the truck also makes it difficult to store and prepare healthier meals. CMV drivers are subjected to a number of physical and psychological stresses inherent in their occupation, including work overload, high mileage exposure, and irregular work/rest schedules. They are also commonly isolated at work and may be exposed to daily frustrations while driving [12]. These combined circumstances can compromise roadway safety and drivers' long-term health $[13,14]$.

\section{Commercial Motor Vehicle Drivers and Health Risks}

The unique demands of CMV driving result in elevated levels of occupational fatalities, injuries, and lifestyle-related illnesses. CMV truck drivers account for 12 percent of all workplace fatalities in the U.S. and consistently rank among the top three occupations in total nonfatal injuries and illnesses $[15,16]$. Additionally, these unique lifestyle characteristics may increase their susceptibility to many health risks, including obesity, cardiovascular disease (CVD), and 
metabolic disorders. Existing evidence suggests that CMV drivers may have overweight and obesity rates (body mass index $[\mathrm{BMI}] \geq 25 \mathrm{~kg} / \mathrm{m}^{2}$ and $\geq 30 \mathrm{~kg} / \mathrm{m}^{2}$, respectively) that are 22 to 36 percent higher than those of the general American population $[1,17]$. Obesity is linked to heart disease, the number-one killer of Americans, in addition to increased prevalence of hypertension (HTN), dyslipidemia, diabetes mellitus (DM), stroke, osteoarthritis, sleep apnea, and several major cancers [18]. The health consequences of obesity and associated disorders may be related to the 12- to 19-year reduced life expectancy in CMV drivers compared to the general U.S. male population [19].

CVD is not only a health concern for CMV drivers, as it is the leading cause of death in the U.S., but may also be a safety concern that can impact their livelihood. Research efforts have not determined whether CMV truck drivers with CVD are at increased risk for a crash (Federal Motor Carrier Safety Administration (FMCSA)) [20]; however, the literature supports that, overall, drivers with CVD are at increased risk for a crash compared to those without CVD. The FMCSA Expert Panel Recommendations reviewed studies that included data on the relative incidence of crashes among comparable individuals with and without CVD and determined that the crash-rate ratio associated with CVD was 1.43 times greater than that of the general driver population. These findings were extrapolated to the average crash risk for a CMV driver. This analysis found that CMV drivers with CVD were predicted to be in approximately 0.11 crashes per year compared to a crash-rate ratio of 0.08 for a CMV driver without CVD [20]. Although the FMCSA Expert Panel concluded the generalizability of these findings to be limited, they provide support that CMV drivers with CVD may be at increased risk for a crash.

\section{Health and Wellness Case Study}

In 2008, a leading U.S. carrier, Schneider National Inc. (SNI) launched a health and wellness $(\mathrm{H} \& \mathrm{~W})$ initiative with Atlas Ergonomics and United HealthCare (UHC) to provide health services for SNI employees, including CMV drivers, at twelve operating centers (OC) located across the U.S. and Canada. Atlas is a leading ergonomic service and technology provider for healthcare, office, and transportation environments. UHC and OptumHealth are operating divisions of UnitedHealth Group, the largest single health carrier in the U.S., which offers a broad spectrum of products and services through health benefits and services. Optum provides health management solutions that address the physical, mental, and financial needs of millions of consumers and thousands of organizations. Optum is committed to collaboration, service, research, development, and understanding the current state of health care, and then driving transformation. Participating OCs offer health and wellness programs to target specific health behaviors and chronic disease prevention and management, ergonomic and injury prevention services, on-site physical and occupational therapy and health screens, nutrition and exercise education and counseling, and overall wellness coaching to approximately 17,000 companyinsured employees. Employee spouses and adult family members of employees are also eligible to enroll in SNI's H\&W Program. Preliminary results from one SNI site participating in the $\mathrm{H} \& \mathrm{~W}$ Program with Atlas and UHC showed a reduction in participating drivers' body mass index (BMI), cholesterol, triglycerides, glucose, and blood pressure and an increase in aerobic capacity after six months. 
The purpose of this Case Study is to detail SNI's H\&W Program with Atlas Ergonomics and UHC and to evaluate the opinions, perceptions, and program satisfaction of participating CMV drivers and program staff. The findings from this Case Study will aid in the development of carrier-implemented $\mathrm{H} \& \mathrm{~W}$ programs in other CMV fleets as well as best practices for implementing such a program. 



\section{CHAPTER 2: METHODS}

To provide an overview of the H\&W Program, the Virginia Tech Transportation Institute (VTTI) team worked with executives and staff at SNI, Atlas, and UHC to accurately detail and describe SNI's H\&W Program. The program is described in terms of participant recruitment, health surveys and assessments testing, health coaching, H\&W Program components and activities, medical referral, and follow-up.

Topics that were covered during the phone interviews included recruitment methods, tests and assessments administered to drivers, health and wellness education, health coaching, health achievements, motivational strategies, and long-term follow-up. All phone interviews were audio-recorded for transcription and analysis. Detailed phone interview procedures as well as a complete list of topics and questions are included in Appendix A.

Online questionnaires were administered to participating SNI drivers, as well as to Atlas and UHC staff to inquire about their opinions, perceptions, and satisfaction with SNI's H\&W Program. SNI and Atlas OC staff assisted with driver recruitment by distributing recruitment cards to eligible drivers; the cards provided information regarding the purpose of the study and how to voluntarily participate in the questionnaire research. Staff was recruited to voluntarily participate in the questionnaire research by e-mail correspondence. Questionnaires took approximately 10 minutes to complete, and participants were compensated with a $\$ 10$ check for completion of the survey (payment was mailed to their preferred address). A total of 94 drivers and 27 staff completed the questionnaire. There were no exclusion criteria based on sex, health, status, or ethnicity; however, all participants were required to be eligible for employment in the U.S., possess a valid Class-A CDL (if a driver), and be currently involved in SNI's H\&W Program. Upon accessing the online questionnaire, respondents reviewed the Informed Consent Form, indicated their consent with an electronic signature, then completed the questionnaire, which collected demographic information and inquired about the participant's experience in SNI's H\&W Program. The driver and staff questionnaires were structured similarly; however, each was geared for the population of interest. A complete list of topics and questions included in the driver and staff questionnaires are included in Appendix B. 



\section{CHAPTER 3: HEALTH \& WELLNESS PROGRAM DESCRIPTION}

\section{Overview}

SNI management worked with Atlas and UHC to design the H\&W Program. SNI financially supports the H\&W Program and regularly coordinates with Atlas and UHC to monitor and evaluate program effectiveness. Atlas oversees and operates the $\mathrm{H} \& \mathrm{~W}$ program by conducting the biometric screens, providing health and wellness coaching, and coordinating health-related events. UHC provides the mail-based biometric screening kits to Atlas and serves as the central point for collecting all biometric data (obtained from SNI personnel by Atlas). UHC aggregates the collected health information from the online health risk assessment and biometric screens to qualify $\mathrm{H} \& \mathrm{~W}$ participants for a health insurance incentive. Atlas and UHC provide guidance to SNI on the structure and development of the program, work with management to provide status updates, and track the program to ensure it continues to reach established goals.

Participants in SNI's H\&W Program are evaluated using two primary tools, an online health risk assessment and a biometric screen. Participants complete an online health risk assessment which includes a subjective, 50-item health survey and a biometric screen to gather objective information on health measures. Atlas and UHC health coaches review the results from the health assessment and biometric screen with participants to identify areas in need of improvement. They provide participants with suggestions to improve their health behaviors and lifestyle, and provide support and coaching as these health behavior changes are made. UHC also offers several health programs that target specific health behaviors and chronic disease management. Health coaches follow up with participants to track their progress, successes, and challenges.

The SNI H\&W Program is currently available to approximately 17,000 eligible employees. Approximately 4,600 employees participated in the program as of 2010. Of these, approximately 33 percent were drivers (of which $54 \%$ were obese).

\section{Participant Recruitment}

Participation in the H\&W Program is voluntary; however, medically insured SNI employees and spouses are offered a health insurance incentive, in terms of a generous monetary donation to their health reimbursement account (HRA), to encourage participation. The incentive program is appealing to employees and appears to be a factor in many employees' decision to participate. One key to building interest and participation in the H\&W Program was the initial rollout of the program. Before the H\&W Program was launched, SNI management worked with their Occupational Health Team to market the program by sending informational materials to employees and their families. These materials included information on the H\&W Program, general health and wellness information regarding obesity, chronic disease, and tips for disease management. These informational packets were mailed to employees' homes and delivered during on-site presentations. Phone calls from the SNI Occupational Health Team were made to employees to inform them of the H\&W Program. Information regarding the program was also included in the quarterly employee newsletter Extra Mile (a newsletter that all SNI drivers and warehouse associates receive), posters at site locations, table tents, and fuel pump toppers (advertisements on fuel islands). Also, kick-off events were held at each participating terminal site. 
Driver recruitment can be challenging as drivers may be fearful of personal medical information falling into the hands of their carrier, and, in turn, being used to disqualify them from driving. Therefore, during driver recruitment, it is important to address this fear early on. Informational materials should report that the data collected from the biometric screens and health assessments are considered health-protected information by the Health Insurance Portability and

Accountability Act (HIPAA) and cannot be accessed by their employer. SNI's H\&W Team also addressed this issue by discussing it in articles published in the Extra Mile newsletter, as well as with groups of drivers during kickoff meetings. SNI employees may go to their own primary care physician for the biometric screens, which may reduce the perception that SNI can access their personal health information.

In addition to recruiting SNI employees for participation in the online health assessment, biometric screen, and health and wellness coaching, UHC coaches also reach out to associates for participation in additional health programs. These programs include smoking cessation, weight loss, nutrition, exercise, heart health (lifestyle modifications), diabetes management (for uncontrolled diabetes), diabetes lifestyle program (for controlled diabetes), and stress management. Members may enroll in any of these programs at any time and without prerequisites; however, in order to qualify for the HRA incentive, employees must participate in the online health risk assessment and the biometric screening.

A technique that SNI plans to use as their H\&W program gains success and popularity is to nominate Benefit Champions (employees who are passionate about the program and have found success). These Benefit Champions would reach out to other associates and be available for questions and coaching. They would also help to generate new ideas for increasing participation in the H\&W Program and other SNI health initiatives.

\section{Health Assessment and Biometric Screen}

The online health risk assessment includes questions related to safety and health behaviors (e.g., seat belt use, nutrition and exercise habits), yearly miles driven, job stress and work satisfaction, eating and exercise habits, completion of preventative health exams, and life stress. Participants can complete the online health risk assessment from any computer with Internet access. Computers with Internet access are available at Atlas locations and SNI terminals, or drivers may choose to complete the survey from their home computer. Once a survey is submitted, it is automatically received by UHC. The biometric screen includes height and weight (so body mass index $[\mathrm{BMI}]$ can be calculated), resting blood pressure, and fasting lipid and glucose analysis (for the calculation of total cholesterol, high-density lipoprotein cholesterol, total cholesterol/high-density lipoprotein cholesterol ratio, triglycerides, and glucose). The H\&W Team believes that offering multiple modes of collection for the biometric screen will increase participation as employees can choose the most convenient option. For example, collection of the biometric screen is available at any of the twelve Atlas and participating SNI terminals. SNI employees may also request a mail kit, which includes a portable test for fasting lipid and glucose analysis and instructions for completing the finger-stick blood test (which is processed by UHC). The results of the biometric results are provided to members within two weeks. About one-third of employees and half of drivers participating in SNI's H\&W Program choose the mail kit option. Another option allows participants to complete their lipid and glucose panel laboratory test at their primary care physician's office and submit the results to Atlas. The online 
health risk assessment and biometric testing are completed independently; however, both must be completed in order for a driver to be eligible for the health insurance incentive.

Once Atlas receives data from the biometric screen, they are able to rate each participant's health profile using a system by which each participant's health profile is rated on a 1 to 5 scale (with 1 representing least severe health status and 5 representing most severe health status). A profile rating $\geq 3$ indicates that at least one biometric screen is at a level that a physician referral is indicated to participate in the H\&W Program. The collected health information is assessed through an identification and stratification predictive algorithm that identifies unhealthy behaviors and risk factors that can be impacted by lifestyle and behavior change. These results are used to administer the incentive program to participants. Employees qualify for incentives based on eligibility, and their incentives are fulfilled through their HRA account. Atlas and UHC coaches use face-to-face, telephone, and mail-based outreach to invite employees that have been identified with risk factors to participate in the coaching programs.

\section{Review and Coaching}

Atlas and UHC coaches review the results from the biometric screen and health assessment with participants one-on-one. During these review, the coaches provide feedback and suggestions to improve health behaviors, as well as establish goals related to problem areas. As confidentiality of private health information is a priority at SNI, Atlas and UHC coaches stress that health information is protected by HIPAA and cannot be discussed with SNI.

Atlas and UHC work together, but also provide independent review and coaching to participants in SNI's H\&W Program. Atlas provides one-on-one, face-to-face wellness coaching; UHC provides one-on-one telephone health coaching. UHC's goal with the telephone coaching is structured to make each call action oriented and directional (i.e., identify realistic goals that will make a difference in meeting the appropriate lifestyle changes). At the end of each call, UHC coaches make a contract with the participant to follow up on the next call regarding progress, challenges, setbacks, etc. Atlas and UHC coaches strive to make each interaction with a participant as personal, efficient, and productive as possible. Drivers may use Atlas or UHC coaching programs or both resources.

It is important for Atlas and UHC coaches to ensure that participants understand their health information, the relevance of this information, and how they can control their health through lifestyle and behavior changes. Throughout the coaching process, Atlas and UHC evaluate each participant's level of commitment, motivation, ability, expectations, and self-accountability using the Transtheoretical Model of Change as a guide [21]. This model assesses an individual's readiness to act on a new health behavior and provides strategies or processes of change to guide the individual through the five stages of change. The five stages of change include (i) Precontemplation, (ii) Contemplation, (iii) Preparation, (iv) Action, and (v) Maintenance [21]. Health coaches cater their coaching techniques around the traits of the participants and their current stage in the model. It is important for health coaches to identify that each participant has long-term motivation to change, motivators, and reasons for wanting to change. Coaches also work with participants to identify what behavior and lifestyle changes they want to make and why. This aids coaches in getting a sense of each participant's commitment and how it compares with the challenges the participant faces. Health coaches employ motivational techniques in their coaching methods by discussing and detailing how drivers can implement positive lifestyle and 
behavior changes into daily life on the road and at home. The H\&W coaches find that taking small steps with non-negotiable goals is a successful strategy for building to larger goals and making long-term lifestyle changes.

Counseling drivers on making healthy food choices and exercising on the road is critical to success, as these are significant barriers to good health. Drivers in SNI's H\&W Program are provided with educational materials, including a Driver's Guide to Exercise on the Road, to supplement coaching. This exercise manual is designed for drivers and includes instructions for developing a simple exercise program and demonstrational pictures of exercises that can be done in or around the truck (to show drivers how to get an effective workout without access to a gym or fitness center). The Driver's Guide to Exercise on the Road includes cardiovascular, posture, balance, strength, and flexibility tips that can be performed with simple resistance bands or without any equipment. A companion document, Driver's Guide to Nutrition on the Road, is also provided and includes suggestions and strategies for making healthier food choices while on the road. Coaches also encourage participants to keep personal logs to track their exercise and physical activity, as well as their diet. During the pilot H\&W Program, coaches provided these logs to participants and instructed them on how to fill them out. Approximately 10 percent of the logs distributed were completed and returned, demonstrating the challenges in asking participants to assist coaches by recording the health behaviors linked to their health outcomes.

Coaches share techniques that have been found successful for other drivers, including packing a cooler with healthy snacks and meals to minimize reliance on fast food and truck stop fare.

Planning ahead for exercise and good nutrition by scheduling workouts and planning, cooking, and freezing meals ahead of time is another helpful tip shared by coaches. When feasible, scheduling rest stops and breaks near Subway ${ }^{\circledR}$ fast food restaurants and other restaurants that offer healthy meal options and near truck stops with accessible parking is another tip. The H\&W coaches noted that taking what they know about health education and coaching techniques and combining this information with real-world driver success stories is key for encouraging the driver population to make health behavior changes. Coaches strive to improve driver attitudes and self-efficacy and convert industry barriers into solutions and positive health behaviors. In the future, the SNI H\&W Team plans to organize driver advocacy groups that have had success in the H\&W Program so they can share their experiences with other drivers.

\section{Follow-up and Long-term Coaching}

Drivers that elect to participate in SNI's H\&W Program receive frequent follow-up from Atlas and UHC coaches who provide support and encouragement. The H\&W coaches try to provide weekly coaching in the beginning and space additional follow-up calls as time goes on. Subsequent health checks (i.e., additional biometric screens and health assessments) are important to show drivers their health improvements, or conversely, areas that need continued efforts to improve. Coaching and motivational techniques that are employed by the H\&W coaches consider the Transtheoretical Model of Behavior Change [21]. This model proposes that people apply cognitive, affective, and evaluative processes as they progress through the early stages of personal change. As people move toward the final stages of Action and Maintenance, they rely on commitments, conditioning, contingencies, environmental controls, and support [22]. H\&W coaches are trained to recognize what stage participants are in and what strategies will be most effective to engage them to progress through the stages. 
Participants can go online and view all their results from the online health risk assessment and biometric screen, as well as the status of their incentives (e.g., when their data was received, when they have met eligibility requirements). Participants can also access their electronic personal health records through a secure portal hosted by UHC. Participants are provided a results summary, an explanation of what their results mean, and action steps to improve their health. Coaches feel that making this information available to participants increases their selfefficacy and their awareness of their progress in the H\&W Program.

\section{Program Components and Activities}

In cases where participants may be at severe risk for disease, as screened from the online health survey and/or the biometric screen, participants are contacted by a UHC health coach and recommended to enroll in an additional health program. UHC offers telephone wellness coaching that specifically targets smoking cessation, weight loss, nutrition, exercise, heart health, and stress management, and two programs that target diabetes management (one for participants with uncontrolled diabetes and another for those with controlled diabetes). UHC noted tremendous success with the QuitPower tobacco cessation program, which rewards non-smokers and incentivizes tobacco users to be tobacco free with lower health insurance premiums [23]. This 6month, telephone-based program uses nicotine replacement therapy and professional coaching to achieve a 35 to 40 percent quit rate. High-risk drivers may also be referred to a physician for a personal consultation.

In addition to the health education, coaching, and programs available for SNI employees and family, SNI's H\&W Program promotes other activities to increase participation and engagement. SNI has endorsed two company-wide programs: Maintain, Don't Gain and Shape Up Schneider. The goal of Maintain, Don't Gain is to prevent holiday weight gain between Thanksgiving and New Year's Day. Participants in the group- and team-oriented Maintain, Don't Gain program receive a toolkit to help them achieve success, including promotional materials, a pledge sheet, tracking tools, and regular e-mail updates that share challenges, tips, and resources to promote health and wellness. A random drawing gives one participating team an opportunity to choose a charity to receive funds donated by the SNI Foundation. Another program, Shape up Schneider, is an eight-week voluntary, individual program designed to generate conversation, increase knowledge, and gain commitment from employees to take steps toward improving and maintaining personal health and fitness. The Shape up Schneider program is a spirited competition to improve the health and well-being of company employees and strengthen the culture of wellness throughout the company.

Employees are encouraged to participate in these optional group programs. Weight loss competitions, similar to the Biggest Loser Competition, are also held at several local operating centers, but are conducted on a smaller scale. Employees sign up for the weight loss competition in small teams, and each participant pays $\$ 10$ to register for the competition. At the start of the competition, Atlas records all participants' initial weight. During the competition, participants are sent e-mails and motivational materials to guide them as they attempt weight loss by making positive health behavior changes to their diets and exercise routines. After 10 weeks, participants are weighed, and the teams with the greatest weight loss are recognized and awarded prize money. SNI and Atlas noted that drivers seem to enjoy the group competitions as there is a respectable amount of driver participation in the Maintain, Don't Gain, Shape up SNI, and weight-loss competition activities. Based on the results from these competitive programs, the 
SNI H\&W Team found that it was more challenging to enlist participation in the company-wide programs rather than in the programs that operate on a smaller scale at the individual terminal locations. They also noticed that non-driver SNI employees (e.g., managers, office staff, and warehouse) were far more likely to participate in these health-promoting activities compared to CMV drivers, thus reflecting the challenges in getting drivers to participate in health promotion programs.

The SNI H\&W Program team believes the inclusion and involvement of family members is a critical factor in the success of the H\&W Program. The H\&W Program is available to spouses of medically insured SNI employees. Thus, family members serve as a support system for the employee, but also can participate with SNI employees. Family members covered under the SNI health insurance plan also benefit from the health insurance incentive.

\section{Medical Referral}

Those participants who score a 3 or greater (on a 1 to 5 scale where 1 represents all normal-range biometrics and 5 represents biometric risk factors for disease) on the rating scale are recommended for follow-up with a physician. Participants who are morbidly obese (BMI > 40 $\mathrm{kg} / \mathrm{m}^{2}$ ) may be referred to a physician for additional weight-loss assistance. Those with untreated moderate to severe hypertension (BP > 160/100 $\mathrm{mmHg}$ ), elevated lipids ( $\mathrm{TC}>240 \mathrm{mg} / \mathrm{dL}$, $\mathrm{TC} / \mathrm{HDL}$ ratio $>6 \mathrm{mg} / \mathrm{dL}$, or $\mathrm{TG}>200 \mathrm{mg} / \mathrm{dL})$ or fasting glucose $(>126 \mathrm{mg} / \mathrm{dL})$ may be referred to a physician for pharmacological treatment. Since the Department of Transportation (DOT) certification requirements will not certify drivers to operate a CMV if they have elevated BP greater than $180 / 110 \mathrm{mmHg}$ or elevated non-fasting glucose above $200 \mathrm{mg} / \mathrm{dL}$, a goal of the $\mathrm{H} \& \mathrm{~W}$ program is to offer personal health awareness and intervention before drivers are assessed by DOT Examiners.

\section{Follow-up}

Atlas offers a 3-, 6-, and 12-month on-site follow-up where participants complete additional biometric screens to track progress. Participants are categorized by risk factor severity to determine if and when they should be invited to participate in a free biometric re-check; however, re-checks are not mandatory. Following the rating system assigned to each participant's health profile, participants with profiles rated a 3 or higher are strongly encouraged to participate in the on-site biometric re-checks offered by Atlas. Health coaches assign target dates for each participant to complete the follow-up and alert participants to schedule a re-check at one of the SNI/Atlas terminals. Mail kit re-checks through UHC are also available; however, these are not free.

UHC personnel reported difficulty in encouraging participants to participate in the follow-ups and biometric re-checks, likely because they are limited to contacting participants via telephone and the additional cost for the mail kit re-check. Atlas coaches reported less challenges in getting participants to agree to the biometric follow-ups; however, most participants complete re-checks once a year. Approximately 18 percent of Atlas-screened participants return for further coaching, but only about 1 percent of Atlas-screened participants return for a biometric re-check within the same year. The majority of participants reported that one screen per year provides sufficient health awareness. Atlas coaches also cite that working with SNI operations to facilitate contact with drivers and routing to SNI/Atlas sites is critical. Each SNI/Atlas site is connected with a Web-based electronic medical records system for secure transfer of medical information across 
sites; therefore, drivers are able to go to any SNI/Atlas terminal in the country, and coaches have access to all of their health information. This enables more convenient follow-up visits for drivers as they are not limited to a single SNI/Atlas terminal. 



\section{CHAPTER 4: QUESTIONNAIRE RESULTS}

Questionnaires were administered to SNI drivers and Atlas, UHC, and SNI staff that had experience with the H\&W Program. Ninety-six driver questionnaires and 28 staff questionnaires were received. The anonymous questionnaires took participants approximately 10 minutes to complete, and all responses were analyzed for content. Although the previous description of SNIs' H\&W Program provides detailed information on the procedures for recruitment, health assessments and programs, health coaching, activities, and follow-up, the questionnaire results below can be used to refine the H\&W Program. 
Table 1. Questionnaire participant demographic information.

\begin{tabular}{|c|c|c|c|c|c|c|}
\hline Group & $\begin{array}{c}\text { Gender } \\
\text { M:F }\end{array}$ & $\begin{array}{c}\text { Age (yrs) } \\
\text { Mean (S.D.) } \\
\text { Range }\end{array}$ & $\begin{array}{c}\text { Marital Status } \\
(n)\end{array}$ & $\begin{array}{c}\text { Experience } \\
\text { Driving CMV } \\
\text { (n:yrs) }\end{array}$ & $\begin{array}{c}\text { Length of } \\
\text { Participation in } \\
\text { H\&W Program } \\
\text { ( } n \text { :Range) }\end{array}$ & $\begin{array}{c}\text { Satisfaction with } \\
\text { H\&W Program } \\
\text { (n) }\end{array}$ \\
\hline $\begin{array}{l}\text { Drivers } \\
(n=96)\end{array}$ & $85: 11$ & $\begin{array}{c}49(10) \\
22-66\end{array}$ & $\begin{array}{l}\text { 70:Married } \\
\text { 21:Single } \\
\text { 4:Living w/ } \\
\text { Partner } \\
\text { 1:Other }\end{array}$ & $\begin{array}{l}7:<1 \text { yr } \\
10: 1-4 \\
24: 5-9 \\
45: 10-24 \\
9: 25-40\end{array}$ & $\begin{array}{l}14:<6 \text { mo } \\
8: 6 \text { mo- } 1 \text { yr } \\
28: 1-2 \text { yrs } \\
17: 2-3 \text { yrs } \\
28:>3 \text { yrs }\end{array}$ & $\begin{array}{l}\text { 32:Very Satisfied } \\
\text { 47:Satisfied } \\
\text { 13:Neutral } \\
\text { 3:Dissatisfied } \\
\text { 2:Very Dissatisfied }\end{array}$ \\
\hline $\begin{array}{c}\text { Staff } \\
(n=28)\end{array}$ & $7: 21$ & $\begin{array}{l}39(9) \\
25-57\end{array}$ & N/A & N/A & N/A & $\begin{array}{l}\text { 4:Very Satisfied } \\
\text { 19:Satisfied } \\
\text { 4:Neutral } \\
\text { 0:Dissatisfied } \\
\text { 1:Very Dissatisfied }\end{array}$ \\
\hline
\end{tabular}




\section{Driver Results}

On the Driver Survey, participants were asked why they chose to participate in SNI's H\&W Program. Drivers were given a list of options and were able to check all that applied to their decision to participate. The following responses and response rates were indicated by driver participants:

- Insurance incentive (67\%)

- Health concerns $(53 \%)$

- Carrier encouragement (39\%)

- Family encouragement $(5 \%)$

- Physician encouragement (5\%)

- Do not know (4\%)

\section{Program Education}

Driver participants were also asked to indicate what educational materials they received from Atlas and UHC and were instructed to check all responses that applied. The following responses and response rates were indicated by driver participants regarding general health education received:

- General nutrition and dietary education $(83 \%)$

- Eating healthy on the road $(75 \%)$

- General exercise information $(74 \%)$

The following responses and response rates were indicated by driver participants regarding education received on more specific health topics. Again, participants were instructed to check all responses that applied:

- Exercising on the road $(64 \%)$

- Weight loss (50\%)

- Hypertension prevention and control (40\%)

- Diabetes prevention and control (35\%)

- Heart health $(27 \%)$

- Stress management $(20 \%)$

- Smoking cessation (16\%)

- No education $(5 \%)$

\section{Health Perception}

Drivers were asked to comment on their overall health since participating in the H\&W Program. Driver participants were instructed to choose only one response, and the following responses and response rates were indicated:

- Health has improved (61\%)

- Health has remained the same $(34 \%)$

- Health has worsened $(<1 \%)$

- Do not know (4\%) 


\section{Program Likes}

Driver participants were asked to comment on what they liked most about participating in the H\&W Program with SNI, Atlas, and UHC. Drivers recognized and appreciated SNI's concern and dedication to driver health, and they liked the convenience and accessibility of the program with the multiple OCs located across the country. Drivers reported they appreciated the fact they did not have to go to a physician's office or take time off work in order to complete the biometric screens provided on-site as part of the H\&W Program. Being able to visit the OCs for health checks and updates without having to make an appointment is appealing to drivers. The financial incentive to participate in the program was noted by drivers as an appealing reason to join the $\mathrm{H} \& \mathrm{~W}$ Program. The following quotes were given by drivers:

- Driver Quote: "It shows concern of Schneider for their drivers to be in good health."

- Driver Quote: "The program is convenient and accessible."

- Driver Quote: "I don't have to visit a doctor office [or] take time off work. [I can] come in without an appointment and get [biometric] numbers to see if [I'm] falling behind expectations or on track."

- Driver Quote: "The financial incentive gives more money for health care."

Drivers reported that the health coaches were helpful, available to answer questions, and conveniently on-site at the participating OCs. Drivers indicated their health coaches worked oneon-one with them to set realistic, health-related goals. Drivers appreciated the health information and education they received from the coaching team, especially the information and tips that addressed health on the road, given their unique mobile lifestyle. The following quotes were given by drivers:

- Driver Quote: “[Health coaches are] always willing to help or give advice [and they provide] clear, easy to understand information in a format that does not require too long to comprehend or read."

- Driver Quote: "[Health coaches give] goals [to work on] that are realistic to improve health."

- Driver Quote: "Personnel are on-site and available to answer questions and [perform] various [health] checks."

- Driver Quote: "[I] have the same [coach] to talk to each time."

- Driver Quote: "The education is in depth and helps with proper diet and exercise."

- Driver Quote: "I like the information on how to be healthy in the truck."

Drivers felt the program encourages them to be more proactive about their healthcare, and the knowledge they gained empowers them to make better decisions regarding their health. Drivers felt the program helped them stay aware of their health and health habits. The following quotes were given by drivers:

- Driver Quote: “Without the program, I probably wouldn't have [the biometric screen] done." 
- Driver Quote: "After talking with the health coaches about [my health assessment] results I know more what to look for, in high cholesterol, good and bad numbers."

- Driver Quote: "[The program helps us] try to stay healthy against industry odds [and makes [us] more aware of our health and opens eyes to our health."

- Driver Quote: "[The program] is a more proactive approach to healthcare."

Drivers reported that the program improves their health, fitness, quality of life, and abilities to perform their daily tasks. In addition to the educational aspect of the program, drivers received the appropriate resources, tools, and support required to help them succeed. The following quotes were given by drivers:

- Driver Quote: "I [can] do more things now that I had a hard time doing before, [and] have gotten in better shape."

- Driver Quote: "Instead of telling drivers to be healthier, it provides information and tools to actually live healthier."

- Driver Quote: "The program has provided a lot of resources [to help drivers]."

Program Dislikes

More than half of all participating drivers (59\%) indicated they had no dislikes regarding the program. The following quote was given by a driver:

- Driver Quote: “There's nothing bad about wanting to improve or maintain a healthy lifestyle."

Driver participants were also asked what they disliked most about participating in the H\&W Program with SNI, Atlas, and UHC. Some drivers felt the initial information they were given regarding the program was vague. Several drivers disliked the required online health assessment. Drivers reported there were not enough Atlas OCs within the SNI terminal network; thus, there were inadequate physical therapy services and fitness rooms at some OCs. Drivers disagreed that physical therapy services were not offered as a primary preventative service. The following quotes were given by drivers:

- Driver Quote: "Ambiguous information [was provided] about participating [in the H\&W program]."

- Driver Quote: "There are not enough [Atlas] locations [within the SNI network] to get the in depth information [needed] [and] there are not enough company sites with physical therapy or fitness rooms."

- Driver Quote: “As a driver, I would like hands on professional physical therapy due to our sitting so much... which is not offered until there is a symptom which we have to go through health insurance." 
Privacy of health information was a concern for many drivers who thought health information could be used against them by their employer:

- Driver Quote: "Sometimes I feel a loss of privacy."

- Driver Quote: "I have concerns over SNI knowing too much about [my] personal business."

- Driver Quote: "The information may be used against [us]."

Some drivers did not appreciate all the health information, educational materials, and program information that was "pushed" on them, though opinions were mixed. One driver requested more information be provided on eating healthy while on the road, and another participant thought the classroom health training should not be part of the work environment. The following quotes were given by drivers:

- Driver Quote: "The constant pushing of health related information, [including] fliers at work, company communication, mailings sent home, and emails."

- Driver Quote: "I'd like more information on how to eat healthy and what kinds of food to buy that can be cooked and eaten in a SNI truck."

- Driver Quote: “[I] don't agree [with] having a mandatory classroom [at] work and health issues tied together."

Some drivers noted that it was difficult to see the Atlas team due to their irregular schedules and hours, especially for those working third shift or late night into early morning hours. Drivers commented that the phone sessions with the health coaches seemed rushed at times and followup was not always consistent. Drivers also noted that many of the education and fitness events were scheduled during times which did not allow their participation. The following quotes were given by drivers:

- Driver Quote: "[It can be] difficult to make an appointment with the Atlas team."

- Driver Quote: "Phone sessions with the health coaches always seem rushed."

- Driver Quote: "Most of the educational and fitness events are held at times which do not allow full participation, like they are scheduled in the middle of the work day."

Drivers also thought the program lacked monetary incentives to encourage participation. The following quotes were given by drivers:

Driver Quote: “[There is a] lack of monetary incentives.” Suggestions for Program Improvement

Many drivers did not have specific suggestions for improving the program; however, they shared positive comments about the H\&W Program. The following quotes were given by drivers:

- Driver Quote: "Do what you are doing, it is a great program!"

- Driver Quote: "The program is well coordinated and informative."

- Driver Quote: "Schneider does a good job with helping drivers." 
Drivers were asked to comment on suggestions they may have for improving the H\&W Program. Drivers thought that participation could be increased and suggested greater availability of the health coaches and more individual time spent between coach and participant. The following quotes were given by drivers:

- Driver Quote: "Host health fair events at company operating centers to let more drivers know that the services are available to them, rather than just handing out printed handouts that are often never read."

- Driver Quote: "Have the wellness coaches available for more calls [and] more frequent calls [in addition to the coaches being on-site] at the wellness centers more often."

- Driver Quote: "[There should be] more time available per appointment [and] more frequent appointments [for drivers and offer] more active help, [such as] exercise monitoring."

Drivers thought increased anonymity may also encourage participation, but did not elaborate on how this could be done:

- Driver Quote: “[Have] more of an anonymous system.”

Drivers suggested providing drivers with more health information tips, even unconventional information (e.g., holistic medicine, supplements). Drivers had mixed feelings about the online health assessment and biometric screen; some drivers suggested including more health tests and others disliked the health assessment. The following quotes were given by drivers:

- Driver Quote: "Find more ways to make health information available to drivers. [I] like the health tips that are posted from time to time at the operating centers [and suggest having more of these]."

- Driver Quote: "[Provide] more unconventional information, like acupuncture and herbal education." Driver Quote: "Include more [health] tests."

Drivers commented their long work hours negatively affected their health. Drivers appreciated the exercise aspect of the $\mathrm{H} \& \mathrm{~W}$ Program, and many suggested increasing the exercise component of the program and opportunities to exercise. Drivers suggested including more SNI terminal locations in the H\&W Program and offering exercise equipment at additional OCs. Another suggestion from drivers was to offer health club memberships for employees and family members to encourage regular physical activity outside the workplace program. One driver suggested setting up a network of participating fitness clubs that drivers would have access to at a reduced rate. Drivers commented that eating healthy on the road is challenging due to the inconveniences of cooking in the truck cab and the unhealthy fare options at truck stops. 
The following quotes were given by drivers:

- Driver Quote: "Having drivers work [fewer] hours [would help them improve their health]."

- Driver Quote: “Group programs at operating centers with fitness improvement programs [as well as] onsite exercise classes and more/better exercise equipment."

- Driver Quote: "Include more SNI terminal locations in the H\&W program [and] equip additional operating centers with exercise equipment."

- Driver Quote: "Offer health club memberships for employees and [their] families [and] set up a network of locations of fitness clubs."

- Driver Quote: "[We] need a way to cook healthy food in the truck; buying meals in a truckstop is not healthy, nor cost-effective."

Drivers voiced that participation could be encouraged through increased incentives:

- Driver Quote: "Additional incentives [should be added] to the program to encourage participation."

\section{Additional Feedback}

Drivers were asked to share additional comments or feedback regarding the H\&W Program, and the majority of comments were positive. Drivers noted that H\&W programs, like SNI's, are rare in the industry, and they appreciated the convenience of on-site access to health advice and coaching, as well as the fitness equipment. Drivers recognized their profession makes them a vulnerable group for developing health disorders and felt the program helped them monitor their health and be proactive in their own wellness plans. Even "healthy" drivers can benefit from the program through early prevention. The following quotes were given by drivers:

- Driver Quote: “[H\&W programs like SNI's are] a need in the industry.”

- Driver Quote: “[I appreciate] not having to see a doctor to get [health] advice.”

- Driver Quote: "[The program is a] good way to keep track of [our] health [which] benefits [us] personally, as well as our job."

Drivers recognized the link between their health and career and appreciated SNI for supporting their health needs. Drivers especially appreciated that the program was provided to them at no additional cost. The following quotes were given by drivers:

- Driver Quote: "[The program is] free and informative... any help [we] can get on the road is appreciated because the job is filled with opportunity to let health deteriorate, but not many opportunities to maintain and improve [health]."

- Driver Quote: "[The H\&W Program] makes [me] take a look at what I'm doing to stay healthy in a job that can easily become unhealthy." 
- Driver Quote: "Too many truckers are out of shape and overweight, anything that would help them be in better shape would make the roadways safer."

Drivers elaborated on the benefits of the H\&W Program, including the improved quality of life they experienced as a result of the program and the financial savings being healthy provides through reduced medical issues. Several drivers noted they would recommend the H\&W Program to others as a result of the benefits they experienced. The following quotes were given by drivers:

- Driver Quote: "The SNI program provides vital information and support in bringing health awareness to the employee."

- Driver Quote: "Every driver should take an active role in their health [and] this program will assist them in doing so."

- Driver Quote: "I feel fortunate working for a company that really does care about the associates and their wellbeing."

Drivers also had negative comments regarding the H\&W Program. Some felt frustrated with the program and thought it was intrusive, while others felt the information they received was overly simplistic. Drivers commented the program does not always consider their irregular schedules; they also felt that participation should remain voluntary. Drivers also agreed the program needed more exposure and marketing to increase participation. The following quotes were given by drivers:

- Driver quote: "[It can be] intrusive and frustrating; [the information provided] is simplistic and doesn't take into consideration what we already know or include in our life."

- Driver quote: "[The program] is not set up for the irregular schedules that drivers are on; the therapists are available but [can be] hard to track down."

- Driver Quote: "More drivers need to know about the availability of the program."

The following responses and response rates were indicated by driver participants regarding their overall satisfaction with the H\&W Program:

- Very satisfied $(33 \%)$

- $\quad$ Satisfied $(49 \%)$

- $\quad$ Neutral $(20 \%)$

- Dissatisfied (3\%)

- Very dissatisfied (2\%)

An overwhelming majority of drivers (95\%) reported they would recommend the SNI/Atlas/UHC H\&W Program to other drivers. 


\section{Staff Results}

Program Education and Training

On the Staff Survey, participants were asked how much education and/or training they give SNI drivers on the following health topics: general nutrition and diet information, general exercise information, weight loss, eating healthy on the road, and exercising on the road. Response options included "way too little," "too little," "about right," "way too much," or "I do not educate drivers on this information" for each question category. The following responses and response rates were indicated by staff participants:

- General Nutrition and Diet Information

- About right (68\%)

- Do not educate drivers on this information (18\%)

- Too little (14\%)

- Exercise Information

- About right (71\%)

- Do not educate drivers on this information (18\%)

- Too little (11\%)

- Weight Loss

- About right (68\%)

- Do not educate drivers on this information (14\%)

- Too little (14\%)

- Way too little (4\%)

- Eating Healthy on the Road

- About right $(71 \%)$

- Do not educate drivers on this information (21\%)

- Too much $(8 \%)$

- Exercising on the Road

- About right (64\%)

- Do not educate drivers on this information (18\%)

- Too little (14\%)

- Too much (4\%)

- Hypertension Prevention/Control

- About right (79\%)

- Do not educate drivers on this information (18\%)

- Too much (3\%)

- Diabetes Prevention/Control

- About right (61\%)

- Do not educate drivers on this information (14\%)

- Too little (25\%) 
- Heart Health

- About right (64\%)

- Do not educate drivers on this information (14\%)

- Too little (18\%)

- Smoking Cessation

- About right (57\%)

- Do not educate drivers on this information (21\%)

- Too little (11\%)

- Way too little (11\%)

- Stress Management

- About right (50\%)

- Do not educate drivers on this information (18\%)

- Too little (29\%)

- Way too little $(4 \%)$

Staff participants were asked to list any additional education they gave SNI drivers as part of the H\&W Program. Staff noted they educated participants on the details of each wellness program and assisted participants in choosing a health program to meet their needs. Staff also helped participants enroll in the program and establish an initial connection with their health coaches. Drivers receive education on primary prevention and how their health impacts their DOT exam. Staff noted they provide informational handouts to drivers to complement the education they receive; online resources are also used to enhance the learning process. Participants in the $\mathrm{H} \& \mathrm{~W}$ Program also receive a packet which includes educational materials, a pedometer, and food journal to help them track their daily eating habits. Staff reported providing education on additional topics, including sleep health and sleep disorders, strength training and ergonomics, and hydration, among other topics of interest. The following quotes were given by staff:

- Staff Quote: "[We] help SNI participants identify the health program that will meet their individual needs [and] educate participants on how the wellness programs work and what each entails."

- Staff Quote: “[All educational topics have] corresponding hand-outs to enhance the teaching process [and they utilize] online resources when appropriate from organizations including the United States Department of Agriculture (USDA), American Heart Association (AHA), Centers for Disease Control (CDC), National Institutes of Health (NIH), Ace Fitness, and websites such as Helpguid.org, eatright.org, diabetes.org, smokefree.gov, sparkpeople.com, and choosemyplate.org."

- Staff Quote: "Additional topics [of education] include sleep health and disorders, strength training, posture training, and ergonomics, pain management, orthopedics, allergies, preventative screenings, holiday eating tips, and hydration." 
- Staff Quote: "[Program participants] receive a Health and Wellness packet in the mail which covers all ranges of topics and includes a pedometer to help them track their steps, as well as a food journal."

\section{Health Assessment and Biometric Screen}

Program staff were asked to rate the overall adequacy of the health testing and assessments that drivers undergo as part of the H\&W Program and if they had suggestions for improving these assessments. The following response rates were indicated by staff participants:

- Adequate (57\%)

- Somewhat adequate (14\%)

- Don't know (29\%)

When asked if they had suggestions for improving the health testing and assessments included in the H\&W Program, 21\% responded "yes" and 79\% responded "no." Suggestions for improvement included incorporating additional health measures (such as exercise capacity), into the biometric screen. Staff suggested rewarding participants for interim improvements to provide additional incentives for driver participation. Staff noted the process for submitting health screens and tests can be confusing for drivers, so clarifying this process is important. Also, highlighting the home test kit option would likely improve participation rates. Staff felt it should be a priority to recruit drivers to participate and keep them engaged in the H\&W Program. Finally, another suggestion for improving the health assessment was to enhance the follow-up with drivers to effectively convey that their health status and participation in the H\&W Program is not shared with their employer. The following quotes were given by staff:

- Staff Quote: "Include an exercise capacity measurement."

- Staff Quote: "Give rewards for improvements each year."

- Staff Quote: "The instructions for how to submit their [health screening and testing] information is still not clear for many, [so] opportunity for education regarding this process when drivers are first hired [would be helpful]."

- Staff Quote: "Prioritizing SNI staff to get drivers through the operating centers for testing [and] enhancing communication [to drivers] about the home test kit option."

- Staff Quote: "Improving the follow-up system for those drivers with high values [regarding their health and the program]."

- Staff Quote: "It's sometimes difficult promoting health testing and assessments because drivers envision ulterior motives on the part of SNI [therefore we need to] convey more effectively to drivers and increase their confidence and comfort that their biometric screen results won't be shared with SNI."

\section{Program Supports}

Program staff were asked to comment on what they thought supports the success of the H\&W Program. Staff stressed the importance of informing participants about the details of the H\&W Program (e.g., what the program entails, as well as ensuring that they know what to expect as program participants). Staff noted that personally inviting or reminding drivers about the 
biometric testing appears to increase driver participation in the H\&W Program. The following quotes were given by staff:

- Staff Quote: "Providing information to drivers about the H\&W program at the time of assessment [is helpful because] drivers are often prepared to participate [at that point]."

- Staff Quote: "Personally inviting or reminding drivers about the biometric testing appears to increase driver participation."

Respondents noted that having the Atlas therapists on-site at the SNI terminals helps facilitate getting drivers involved in the program. It is most convenient for the drivers to have everything happen on-site at the terminal, including testing and assessments, coaching, and education.

Flexible scheduling was also mentioned by staff as a feature of the H\&W Program that works well. Staff felt that the biometric screens and the home test kits work well for objectively assessing driver health. Also, discussing assessment results with participants and providing faceto-face education and one-on-one coaching works well to keep participants engaged and motivated. Staff noted that working one-on-one with drivers often leads to the development of a relationship and positive rapport between the therapist and driver, which is helpful for individual success and the success of the H\&W Program. The following quotes were given by staff:

- Staff Quote: "Having the Atlas therapists on-site at the SNI terminals helps facilitate [getting drivers involved in the program]."

- Staff Quote: "It is convenient for drivers to have everything happen on-site at the terminal [including testing and assessments, coaching, and education]. Drivers appreciate not having to take the time to go off-site."

- Staff Quote: "Discussing assessment results with participants and providing face-to-face education and one-on-one coaching [works well]. Working one-on-one with drivers often leads to the development of a relationship and positive rapport between therapist and driver."

A focus of the program is helping participants make small and manageable lifestyle changes that will improve their overall health and wellness. Providing program members with the tools necessary for success, including Wellness Calls that offer additional support and knowledge, is also cited by program staff as a support. Maintaining a regular schedule for contacting participants to hold them accountable for individual, health-related goals is important. The following quotes were given by staff:

- Staff Quote: "Helping participants make small and manageable [lifestyle] changes that will improve their overall health and wellness [works well]."

- Staff Quote: "Keeping scheduled calls with participants to hold them accountable for the personal, [health-related] goals they set with their health coaches [is important]."

Staff highlighted the smoking cessation program and the education on blood pressure, diet, aerobic exercise, and cab ergonomics. These program components support the goals of the H\&W Program by addressing health concerns which are prevalent among CMV drivers. These 
programs are available at no cost to drivers as part of their medical benefits, which further incentivize drivers to participate. Further, no-cost access to tobacco cessation specialist and nicotine replacement therapy supports the program, as many drivers utilize these supports to address the prevalent nicotine use in the industry. The following quote was given by staff:

- Staff Quote: "The smoking cessation [program] and the education on blood pressure, diet, aerobic exercise, and cab ergonomics all work extremely well [and are] available at no cost to drivers as part of their medical benefits."

Staff believed that the HRA incentive was enticing to drivers and appreciated that participants were only eligible for the incentive if they completed the program (rather than enrolling and putting forth little effort). The following quote was given by staff:

- Staff Quote: “The HRA incentive was enticing to drivers [and] participants [were] only eligible for incentives if they completed the program, rather than just enrolling and putting forth little to no effort toward healthful momentum."

\section{Program Challenges}

Program staff commented on the challenges they face regarding the H\&W Program. Staff noted that participation in the health assessments and preventative screenings could be increased, and they attributed much of the lack in participation to drivers feeling that their job may be in jeopardy if their health is considered poor. Staff indicated that participation could be improved if they could eliminate this misconception and ease drivers' fears. The following quotes were given by staff:

- Staff Quote: "Participation in the health assessments and preventative screenings [could be increased]."

- Staff Quote: "Drivers may feel that their job may be in jeopardy if their health is considered too poor."

Staff commented that one of the biggest challenges they face is getting drivers the motivation to want to change their unhealthy habits. Encouraging program participants to take the initiative to commit to healthy changes and motivate themselves is an area that needs improvement. Staff felt that employee participation in the smoking cessation program was high; however, employees were not taking advantage of other wellness programs offered (such as weight management, heart health); greater emphasis on these additional programs is needed to increase enrollment and improve the success of the H\&W Program. The following quotes were given by staff:

- Staff Quote: "One of the biggest challenges [we] face is getting drivers to want to change their unhealthy habits."

- Staff Quote: "Employees are not taking advantage of other wellness programs offered, i.e. weight management, heart health, etc.; a greater emphasis on these additional programs [is needed]." 
Staff also recognized the challenges drivers face with respect to keeping scheduled appointments; this can make completion of the program a challenge for drivers. Drivers also struggle with staying on-track with exercise and nutritional goals due to constant changes in their work schedules and shifts. The following quote was given by staff:

- Staff Quote: "Drivers also struggle with staying on track with exercise and nutritional goals due to constant changes in their work schedules and shifts."

Suggestions for Program Improvement

Staff were also asked to provide suggestions and recommendations for improving the $\mathrm{H} \& \mathrm{~W}$ Program. Communicating the existence of the H\&W Program and its benefits to employees and making it easily accessible were suggested as ways to increase the success of the program. One suggestion was to increase the presence of the H\&W Program by focusing on staff involvement and leadership. Individual departments inside SNI should value the importance of the program; this could be accomplished by providing education on the H\&W Program for all levels of management personnel at SNI. Another suggestion was to provide more education and training for the wellness coaches on how to coach long-haul drivers that are away from home. The following quotes were given by staff:

- Staff Quote: "Communicating the existence of the H\&W program and its benefits to employees and making it easily accessible."

- Staff Quote: "Increasing presence in the field and focusing on staff involvement and leadership."

- Staff Quote: "Individual departments inside of SNI need to value the importance of the program; [therefore], education for all levels of management personnel."

- Staff Quote: "More education and training for wellness coaches on coaching long-haul drivers."

Staff felt that increasing the limited time allotted for health education during classes for new hire drivers and improving the quality of the educational handouts and pamphlets would improve the educational component of the H\&W Program. Staff commented that educating drivers on all forms of nicotine replacement therapy and pharmacotherapy should be covered in the informative sessions and materials. Staff also recommended giving each new hire employee a handout that provided information about the H\&W Program, services, therapies, and programs provided, and where services are offered. Making health-related podcasts and videos available to drivers that are accessible online over the SNI intranet was another suggestion for program improvement. Improving the personal contact between therapists and drivers was another suggestion for program improvement. 
The following quotes were given by staff:

- Staff Quote: "Give each new hire employee a handout with information about the H\&W program, services, therapies, and programs provided, and where services are offered and each occupational clinic site is located."

- Staff Quote: "Make health-related podcasts and videos available to drivers that are accessible online over the Schneider intranet [and] improve the quality of the educational handouts and pamphlets given to program participants."

- Staff Quote: "Enhance the overall quality of the program and services, including allotting additional time to educate drivers about the program, health, and wellness, during driver training."

- Staff Quote: "Improve the personal contact between therapists and drivers and increase the limited time that is allotted for health education during classes for new hire drivers."

Staff reported that drivers want additional information on alternative healthcare (e.g., holistic medicine) and better food choices. One respondent suggested that farmer's markets should be made available at truck stops, thereby, allowing drivers to have access to fresh and healthy fruits and vegetables. Staff noted that drivers need more time to get to an occupational clinic site and more access to these sites; thus, expanding the network and increasing the number of participating clinic sites would help address this issue. Another related suggestion by staff was to have an on-site wellness coach available to drivers when they are not on the road. The following quotes were given by staff:

- Staff Quote: "Farmers markets at truck stops."

- Staff Quote: "Drivers need more time to get to an occupational clinic site and more access to these sites."

The staff reported that drivers appeared to have trouble submitting their laboratory results from their physicians to $\mathrm{H} \& \mathrm{~W}$ Program personnel, so streamlining that process and making it easier to understand was recommended. Program staff realized the importance of consistency between occupational clinic sites regarding facilities and workout equipment, which they are slowly addressing. Providing drivers with additional tools for health success on the road, such as a refrigerator to store perishable foods in their truck cabs, was another staff recommendation. Providing drivers with time on the job to take short exercise breaks was suggested by one staff member. Staff also noted that drivers often do not drink enough water during the day because they do not have the time for frequent restroom breaks; perhaps a schedule that allowed for more frequent breaks would encourage them to adopt these healthy habits. The staff also indicated that encouraging participants to be more active during their day (e.g., daily steps goal or organizing a walking program) might increase daily, low-impact, and low-intensity activity. Staff also felt drivers could benefit from a stretching program to improve flexibility and alleviate musculoskeletal pain. The following quotes were given by staff:

- Staff Quote: "Participants seem to have trouble understanding how to submit their laboratory results from their physicians." 
- Staff Quote: “Consistency between occupational clinic sites regarding facilities and workout equipment."

- Staff Quote: "Provide drivers with additional tools for health success on the road, such as a refrigerator to store perishable foods in their truck cabs."

- Staff Quote: "Provide drivers time on the job to take short exercise breaks."

- Staff Quote: “Encourage a daily steps goal or organize a walking program.”

Staff reported that providing additional incentives for drivers to get involved with their health exercise and nutrition habits would increase participation as drivers seemed to respond positively to incentives. Attaching incentives to early participation or completion of biometric re-checks may encourage drivers to become more actively involved with their coaches and increase their success in making positive lifestyle changes. Consistent follow-up with drivers through phone calls, text messaging, and e-mail was another staff suggestion. The following quotes were given by staff:

- Staff Quote: "Provide additional incentives for drivers to get involved with their health and be accountable for their exercise and nutrition habits [and] celebrate interim successes with additional rewards or incentives."

- Staff Quote: "Attach incentives to early participation or completion of biometric rechecks."

- Staff Quote: “Consistent follow up with drivers through phone calls, text messaging and email."

Several staff respondents had no suggestions for improvement. The following quote was given by staff:

- Staff Quote: “[We are] provided with excellent resources and have responsive and supportive colleagues they can contact when assistance is needed."

\section{Additional Feedback}

Staff were given the opportunity to provide additional comments regarding SNI's H\&W Program. One staffer felt the program had a good start, but there was room for further improvement. Staff commented that if associates receive more information about the H\&W Program and services they are more likely to better understand the program, enroll sooner so they can get their full HRA benefits, and be proactive in their health and wellness. As the program is not mandatory, staff reported that many of the drivers that would benefit most from the program are hesitant to participate. Staff also reported that it would be ideal to perform biometric screens on all associates, not just those who carry UHC insurance. The following quotes were given by staff:

- Staff Quote: "If associates received more information about the $H \& W$ program and services they may understand [better] and enroll sooner so they can get their full HRA benefits and be proactive in their health and wellness." 
- Staff Quote: "The program is not mandatory [so] many of the drivers that would benefit most from the program are hesitant to participate."

- Staff Quote: "Perform biometric screens on all associates, not just those who carry the UHC [insurance]."

- Staff Quote: "The HRA incentive is helpful for increasing enrollment in the program."

Staff commented that it would be ideal if the occupational clinics could get involved with local gyms so drivers could join at a discounted rate. Staff reported that it was very beneficial to have therapists on-site for wellness and injury prevention; this saves money as drivers respond better to personal attention and education. Staff commented that most participants are very busy and sometimes hesitate to take the time for calls from health coaches and program staff so having other means of communication in place is important. The following quotes were given by staff:

- Staff Quote: "It would be nice if the occupational clinics could get involved with local gyms so drivers could go to them around the country for a discounted rate."

- Staff Quote: "It is very forward thinking to have therapists on-site for wellness and injury prevention."

- Staff Quote: "These drivers need personal attention and education [that is] meaningful to them."

Staff highlighted that a wellness program is only one component in the promotion of a healthy lifestyle; it is important to consider other areas, such as food and fitness options at truck stops. It is helpful for drivers to have access to coolers in their truck cabs so they have more control over their diet. A creative solution to increase driver access to exercise may be to have exercise equipment at certain truck stops. The following quotes were given by staff:

- Staff Quote: "It is helpful for drivers to have access to coolers in their truck cabs so they have more control over their food, i.e. fresh fruit, vegetables, yogurt, etc."

- Staff Quote: "Exercise is tough for drivers since they spend so much time in their truck cab. A creative solution may be to have exercise equipment available at certain truck stops, which is something another trucking industry is incorporating. Walking around parking lots at a good pace is another option."

- Staff Quote: “List calorie counts at truck stop vendors and have a poster or handout listing 10 healthy snacks to take on the road."

Staff reported that overall the program was excellent, but it was difficult to understand why participation was so low for the drivers:

- Staff Quote: "Overall, the program is excellent and it's hard to understand why every associate wouldn't want to participate; the onsite coaching experience can only benefit the associate regarding their health and wellness." 


\section{Program Satisfaction}

The following responses and response rates were indicated by staff participants regarding their overall satisfaction with the SNI/Atlas/UHC H\&W Program:

- Very satisfied (14\%)

- Satisfied (68\%)

- Neutral (14\%)

- Very dissatisfied (4\%) 



\section{CHAPTER 5: SUMMARY}

\section{Summary of Driver Opinions and Perceptions}

\section{Driver Satisfaction and Program Likes}

Overall, the majority of drivers were satisfied with SNI's H\&W Program. The majority of drivers reported their health had improved since participating in the program and they would recommend the program to other drivers. The insurance incentive and health concerns were the primary reasons why drivers participated in SNI's H\&W Program. Drivers liked that their carrier was concerned about drivers' health. Drivers also liked the biometric screen they participated in, and some suggested additional health tests be included. Drivers expressed positive opinions about the Atlas and UHC health coaches, stating the coaches were accessible, helpful, gave good advice, were easy to understand, and helped them reach realistic goals to improve their health. Drivers liked the amount of education they received that focused on how to be healthy with their unique lifestyle. Drivers also felt the accessibility and convenience of the on-site clinics and staff improved their chances of success with the program. Drivers reported their participation in the program made them more aware of their health and lifestyle choices and provided them with the tools to take a more proactive approach to improving their health.

\section{Driver Suggestions for Improvement}

Drivers suggested that one way to market the H\&W Program and its available services would be a company health fair. Drivers reported that more Atlas on-site clinics were needed to better serve the needs of the drivers. Some drivers did not like the online health assessment and suggested the H\&W Program should focus on the biometric testing. However, some drivers expressed concerns that their private health information would be "leaked" to their employer or that negative health results would be used against their employment status; thus, drivers indicated the program should have more anonymity. Some drivers felt they received too much information (e.g., fliers at work and company communications, in addition to mail and e-mails) regarding the program. Drivers also wanted more access to health coaches via face-to-face meetings and phone calls so they could receive more active monitoring and assistance, including exercise monitoring and coaching. Drivers liked the exercise aspect of the H\&W Program and wanted more opportunities to exercise, including equipping additional OCs with exercise equipment. Drivers who worked third shift or rotating schedules indicated that scheduling meetings with Atlas employees during “off” times was often difficult.

\section{Summary of Staff Opinions and Perceptions}

\section{Staff Satisfaction and Program Likes}

Overall, the majority of staff were satisfied with the H\&W Program. Staff felt the education and training they provided drivers regarding a variety of health topics were about right, though some had suggestions for improving the education offered to drivers, including more information about the H\&W Program and services and the HRA benefits program during driver training and orientation. Staff indicated that educating the drivers about the H\&W Program a second time during their initial assessment increased participation in the H\&W Program. Staff reported that carrier management would be better able to assist and understand the benefits of the $\mathrm{H} \& \mathrm{~W}$ Program if they received information on how the program worked. Staff felt the health testing and assessments were adequate and had few suggestions for improvement, such as streamlining 
the biometric screens and test kits so employees can submit their laboratory results from their physicians to program personnel. Staff stressed the importance of building a rapport with drivers and making sure drivers were aware their participation in the program would not jeopardize their job status. Most staff agreed that discussing the assessment results in a face-to-face meeting worked well for developing an open and frank relationship between coach and driver. Having full-time physical and occupational therapy available for drivers and offering a variety of programs that target specific health needs, at no cost to company-insured drivers, were key benefits of the H\&W Program.

\section{Staff Suggestions for Improvement}

Staff agreed that increasing the number of on-site Atlas clinics within the SNI network of terminals would benefit the H\&W Program. Staff agreed that participation in the program, especially among drivers, could be improved by increased marketing and communication of the program and its benefits. They realized benefits participants in the program could expect to achieve could be improved by enhanced personal attention, individualized coaching, and encouraging participants to take more initiative and demonstrate self-motivation to committing to healthy lifestyle (e.g., staff noted that many drivers don't want to change their unhealthy habits and are looking for a "quick fix" to their health problems). With the exception of the smoking cessation program, employees were not taking advantage of many of the other wellness programs offered; therefore, informing employees about the other programs could increase drivers' use of these other health programs. Health podcasts and videos regarding specific health topics was another suggestion to keep drivers informed, educated, and engaged about the $\mathrm{H} \& \mathrm{~W}$ Program. Staff recognized that drivers face challenges in keeping scheduled appointments; thus, understanding these challenges and being flexible is key for maintaining a positive relationship with drivers. Staff also suggested that providing drivers with opportunities for brief exercise breaks during the workday would keep them engaged in the $\mathrm{H} \& \mathrm{~W}$ Program. 


\section{CHAPTER 6: LESSONS LEARNED}

The H\&W team was asked to discuss lessons learned from their experience in organizing and implementing SNI's H\&W Program, including what works best, what can be improved upon, and tips and techniques they have learned throughout the implementation process.

Regarding what works best, the team discussed the following strengths of the SNI H\&W Program:

- The online health risk assessment and biometric screening program has been an overwhelming success that has enabled the team to accurately identify and prioritize employees for health coaching, health programs, and physician referrals.

- Offering multiple modes of collection for the biometric screen increases participation.

- Providing easy access to on-site healthcare that is convenient for participants promotes participation. The availability of Atlas coaches on-site at SNI terminals improves participation and results, as well as the rapport between coach and driver.

- Employees appreciate the health insurance incentive program, which increases program participation.

- Effective communication between all players (SNI management, Atlas, UHC, and SNI participants) was key for program success.

When asked to discuss challenges they have faced and what can be improved upon regarding the program, the $\mathrm{H} \& \mathrm{~W}$ team acknowledged the following:

- It is often a struggle to engage drivers to actively participate in the program due to confidentiality concerns. The $\mathrm{H} \& \mathrm{~W}$ team believes driver distrust is one of their biggest barriers regarding participation in the H\&W Program.

- The most challenging health behaviors to improve among CMV drivers included tobacco cessation and reducing BMI.

- Infrastructure needs to be addressed to offer a healthy work environment that includes nutritious meal and snack options, opportunities to exercise, and facilities that promote exercise (appropriate equipment, mobile equipment, shower/locker room facilities, etc.).

The H\&W team shared the following techniques and tips for implementing a successful, carrierdriven $\mathrm{H} \& \mathrm{~W}$ program:

- Custom marketing techniques (such as pump toppers and mailing programs) that target drivers are helpful for increasing participation among drivers.

- Engaging participants early in the process is a critical predictor for long-term success. The $\mathrm{H} \& \mathrm{~W}$ team estimated that 30 to 40 percent of participants make significant progress toward individual goals with early guidance and support from coaches. 
- It is important to disclose to participants that the goals of the H\&W Program are to improve employee and family health rather than to identify "unhealthy" drivers to target for termination. Drivers may be fearful of personal medical information falling into the hands of their carrier. Thus, it is important to address this fear early on in the program rollout.

- It is important to develop a one-on-one relationship with drivers and to establish a positive rapport. Drivers want to have advocates who understand their health challenges.

- Family involvement is particularly important for individual success. Participation by a spouse and/or family member in the $\mathrm{H} \& \mathrm{~W}$ Program is a huge predictor for success.

- Providing education and coaching materials that cater specifically to drivers and the challenges they face, such as healthy eating and exercising on the road, demonstrates the company's care and concern for their drivers.

- Drivers are more likely to accept and appreciate advice if it is coming from other drivers. Thus, a handbook of tips and techniques that other drivers have had success with is helpful in reaching drivers.

- Working within the confines of drivers' work schedules is important.

- Shedding light on common health myths and misperceptions is recommended. It is also important for participants to know their numbers from the biometric screen and to understand what those numbers mean. If they understand their current state of health, they can better convert that knowledge into positive health behavior changes.

- It can be difficult to assess each driver's level of commitment; however, this is where the health coach's motivational techniques and experience with the driver population are employed to recognize what stage members are at in the model and how to engage them to progress through the stages. The $\mathrm{H} \& \mathrm{~W}$ coaches also work with participants to establish internal sources of motivation for participants rather than external sources. An example of an internal source of motivation is a desire to lose weight so that the drivers may play with their kids without tiring. An example of external motivation is a desire to lose weight to win a workplace competition. People who are internally motivated are more likely to initiate efforts themselves, and this is a predictor for long-term success. External incentives, such as money and prizes, work well, but usually have only short-term effects. It can be challenging to build an individual's internal motivation, but this is where oneon-one coaching comes into play.

- The importance of maintaining health awareness should be stressed. Being aware of how they feel, rather than focusing on numbers, is a good indicator for progress. For example, increasing fruit and vegetable consumption and reducing processed foods from the diet may not reflect immediate changes on the scale; however, the participant may feel better, have more energy, and feel less fatigued. 
- Multiple barriers and opportunities for setbacks should be anticipated. Coaches work with participants to identify potential barriers and setbacks before they happen to develop a unique and reasonable plan for addressing them.

- Management support is critical for implementing and maintaining the program. If management is not fully committed at the launch, it will likely reflect in poor marketing, and recruitment will suffer. Financial support from management is also needed as the program is launched; this includes activities regarding the rollout and informational activities to increase awareness of the program. Likewise, employees will be more likely to actively participate in the H\&W Program if it is viewed as a priority for upper management. 



\section{CHAPTER 7: RECOMMENDATIONS}

CMV drivers face many barriers and challenges in attaining a healthy lifestyle. Even small, positive health changes, such as limiting soda consumption or incorporating 15 minutes of daily physical activity, can significantly impact health status. Often small changes snowball into larger changes, which result in goal attainment. A corporate $\mathrm{H} \& \mathrm{~W}$ program is only a piece in the larger promotion of healthy living on the road for CMV drivers; however, educating drivers on health and wellness and empowering them to make positive steps toward healthy living using the knowledge and tools they acquire in the $\mathrm{H} \& \mathrm{~W}$ Program is a positive step in the right direction. Several recommendations resulted from the current study with drivers and staff participating in SNI's H\&W Program:

- Make employees aware of the H\&W Program and market all the accompanying programs, as well as the benefits of participating, to gauge interest and participation. A strong educational component is an important part of any $\mathrm{H} \& \mathrm{~W}$ program; thus, making sure all parties (health provider, carrier, employees, etc.) have the appropriate knowledge will improve outcomes.

- Having a sizeable network of on-site occupational health clinics improves accessibility and convenience for participants. It was convenient for drivers to have access to on-site Atlas clinics and health coaches at the SNI OCs (offering flexible scheduling for assessment and coaching).

- A significant barrier to driver participation was concern over privacy of health information and disclosure to their employer. Addressing these concerns is critical for increasing driver participation.

- The biometric screen is an effective health assessment as it yields objective health data that is easily interpreted. Providing multiple options for completing the biometric screens, (i.e., on-site assessments, home-test kits, and physician assessments), offers participants more flexibility and increases participation.

- Develop trust and a positive rapport between drivers and health coaches. Regular communication with health coaches, individualized coaching sessions, and follow-up phone calls were all recommended to develop a mutually beneficial relationship between health coach and participant.

- Exercise coaching and monitoring is an important part of the H\&W Program and an area that many drivers were uncomfortable pursuing on their own. Provide all employees with opportunities for brief exercise breaks during the workday as a way to promote health activity.

- One of the key benefits in the $\mathrm{H} \& \mathrm{~W}$ Program was the variety of health programs that targeted specific health needs at no cost to employees.

- Offer health podcasts, discussion forums, and videos that drivers can access on their own time, this may keep them engaged in the program. 
- Ensure the program is flexible to meet the needs of all employees, including third shift workers and those with irregular schedules.

- Reward active participation with health and financial incentives as it encourages employees to actively participate. Incorporate additional rewards program for attainment of interim goals to encourage participants to work toward specific health goals. 
APPENDIX A: PHONE INTERVIEW SCRIPT AND PROCEDURES 


\section{Schneider's H\&W Program with Atlas Ergonomics}

\section{OVER-THE-PHONE: Greeting and Informed Consent (5 minutes)}

- Hello, our names are NAME and NAME. We are researchers at the Virginia Tech Transportation Institute. We want to thank you for taking the time to share your thoughts and opinions with us today.

- I want to start by confirming that you had a chance to read over the informed consent document that we e-mailed to you?

- If no: Please take a moment and read through the informed consent form now and then we can discuss any questions you might have about the informed consent specifically or the project in general. (Note: If participants have not read the ICF and does not have the ICF in front of them to read they will be politely reminded that they can't participate in the phone interview).

- If yes: Great. Let me go over some key parts of the consent form and find out if you have any questions for me.

\section{PURPOSE}

- Purpose of this interview is to discuss the Schneider H\&W Program provided by Atlas Ergonomics. This information will help us develop a set of recommendations for implementing and maintaining a successful health and wellness program for commercial drivers that may be used by other companies.

- We're going to ask you a series of questions to collect some details regarding the Atlas H\&W Program with Schneider drivers.

\section{CONFIDENTIALITY}

- This discussion is strictly for research purposes, we are not selling anything and we will not connect anything you say with your name.

- We are recording the discussion so please speak loudly and clearly so that we get a good recording of your comments.

- We will make a transcript of our discussion, but we will not match comments with names.

- If you feel uncomfortable, you can refuse to answer a question or you may stop the questioning at any time.

- Your participation or lack of participation will have no impact on your job.

\section{LOGISTICS}

- This meeting will run for a maximum of 1 hour but may be shortened according to participants' time constraints. We are very appreciative of the time that you are spending and will honor it by not running over.

\section{COMPENSATION}

- You will not be compensated for your participation in this phone interview. 


\section{VERBAL CONSENT}

- Do you have any questions?

- I want to let you know that by participating in this interview you confirm that you are at least 18 years old and are currently working with the Schneider/Atlas Health and Wellness Program. In addition, you acknowledge that you have read the consent information and give your voluntary consent to participate in this study.

- Now I need to ask (each of) you for your verbal consent to participate in this interview. (Name) - Would you like to participate in this study? (Go through each name and mark down consent-yes or no)

- If yes: Thank you! Now we can go ahead and get started.

- If no: Thank you very much for your time.

The following are primary probes. Secondary probes may be used and will depend upon the issues that arise during the discussion. Secondary probes will not stray from the general line of questioning. Time allotments for each set of questions are estimates and may be changed if more or less time is required for a particular set of questions.

\section{Introductions and Warm-up (15 minutes)}

\section{Facilitator Question/Directions:}

- To get started, I'd like to know your position(s) at (Schneider or Atlas) and what you do as part of the H\&W Program.

- Activity: If multiple participants are in the interview, do a round-robin. Make sure and check in with the participant(s) to ensure you have captured their role(s) with the H\&W Program

- Let's take a moment and discuss your role(s) in the program.

- If unsure or need more information ask: Can you tell me a little bit more about what you do as part of this $\mathrm{H} \& \mathrm{~W}$ Program?

\section{Time Check: 15 minute max}

\section{$\underline{\text { V. Recruitment/Inititation into H\&W Program (10 minutes) }}$}

\section{Facilitator Question:}

- Can you tell me about how drivers are recruited to participate in the H\&W Program? Are they selected? Are drivers screened for participation? Do drivers volunteer? Is it a mandatory program or are there plans to make it a mandatory program?

- Activity: Note the recruitment process varied depending on the type of sleep apnea. If necessary make separate pathways for different ways drivers begin the H\&W Program.

\section{Driver Health Assessments/Testing}

\section{Facilitator Question/Directions:}

- Once the driver is initiated into the H\&W Program, can you please walk me through the health assessments they undergo? Do all drivers complete all assessments? How long 
does it take for drivers to complete this battery of assessments? How often are drivers reassessed?

- Are drivers resistant to completing health assessments? Which ones? How does Atlas overcome driver resistance?

\section{Education}

\section{Facilitator Question/Directions:}

- Can you please detail the education provided to drivers regarding health and wellness? What topics are covered, i.e., nutrition, exercise, healthy living on the road? Do drivers receive one-on-one education or are they taught in a group setting? Do drivers receive specialized information to cater to their disorders and/or interests? Are drivers provided any written materials, handouts, etc. that they may refer to later?

\section{Health Coaching}

\section{Facilitator Question/Directions:}

- Does Atlas staff work with the driver to set individual goals? How are these goals monitored? What kind of coaching/motivational techniques does Atlas employ to help drivers meet their goals? What is the most effective tool? Is group coaching helpful? Does Atlas employ a rewards system for drivers that stay on track?

- How does Atlas staff handle drivers that are not making progress toward their goal(s)?

\section{$\underline{\text { IX. Long-term Driver Follow-up }}$}

\section{Facilitator Question/Directions:}

- Once a driver has met his/her goals, does Atlas continue to follow up and check in on the driver? If so, how is this accomplished? Does Atlas continue monitoring the driver with health assessments and tests?

- Can drivers "drop out" or "quit" the program whenever they wish to? Is there an incentive for the driver to remain in the program? If so, how does this work?

\section{$\underline{\text { X. Closing Suggestions (10 minutes) }}$}

\section{Facilitator Question/Directions:}

- In closing, I'd like to ask if there was an important issue that you think should've been covered during this interview that wasn't covered. Is there something that I did not ask about that you feel is important to discuss regarding the H\&W Program with Schneider and Atlas? If so, please tell us now-your opinions are important to us.

- Activity: Open discussion. If multiple participants, make sure quiet ones get to contribute by asking each person specifically if you covered everything he/she wanted to cover.

Thank you for your time today and for sharing your thoughts and opinions with us. We really appreciate it! 
APPENDIX B: DRIVER AND STAFF QUESTIONNAIRES 


\section{DRIVER SURVEY}

Thank you for taking the time to complete this survey. The goal of this survey is to understand how you feel about Schneider's Health and Wellness Program with Atlas Ergonomics. Please be assured that your answers will be kept confidential.

\section{Please select your gender.}

Male

$\square$ Female

\section{What is your marital status?}

$\square$ Single (includes separated, divorced, or widowed)

$\square$ Married

$\square$ Living with partner

\section{Please select your age category.}

$\square$ Under 25 years

口 25 to 34 years

口 35 to 44 years

口 45 to 54 years

口 55 to 64 years

口 65 to 74 years

$\square 75$ years and older

\section{How long have you driven a commercial motor vehicle?}

$\square$ Less than 1 year

$\square 1$ to 4 years

口 5 to 9 years

口 10 to 24 years

口 25 to 40 years

$\square$ Over 40 years 
5. Please indicate the type of Commercial Driver's License (CDL) and Endorsements that you hold. (select all that apply)

\begin{tabular}{ll} 
& \multicolumn{1}{c}{ Endorsements } \\
$\square$ Class A & $\square(\mathrm{P})-$ Passengers \\
Class B & $\square(\mathrm{T})-$ Doubles/Triples Trailers \\
$\square$ Class C & $\square(\mathrm{N})-$ Tank Vehicle \\
$\square$ None & $\square(\mathrm{H})-$ Hazardous Materials (HazMat) \\
$\square$ Other (please describe): & $\square(\mathrm{X})-$ Combination of Tank Vehicle \\
& and HazMat \\
& $\square$ None
\end{tabular}

6. How long have you been a participant in Schneider's Health and Wellness Program with Atlas Ergonomics?

Less than 6 months

a months to a year

प 1 to 2 years

口 2 to 3 years

3 to 4 years

Over 4 years

7. Why did you choose to participate in the Schneider's Health and Wellness Program? (check all that apply)

I was concerned about my health

My carrier encouraged me to participate

My family encouraged me to participate

Don't know

Other. Please explain:

8. Please indicate the education you received while participating in Schneider's Health and Wellness Program: (check all that apply)

Nutrition/diet-general information

Exercise-general information

Losing weight

Eating healthy on the road

Exercising on the road

- Hypertension prevention/control

口 Diabetes prevention/control 
Other: (please explain)

8. What known health conditions did you have prior to participating in Schneider's Health and Wellness Program? (check all that apply)

High blood pressure

$\square$ Overweight/obesity

口 Diabetes

$\square$ Heart disease

$\square$ Sleep apnea

$\square$ Other(s): (please list)

口 Don't know

9. Since becoming a participant in Schneider's Health and Wellness Program has your overall health improved, worsened, or remained the same?

$\square$ Improved

a Worsened

$\square$ Remained the same

$\square$ Don't Know

10. Overall, how satisfied are you with Schneider's Health and Wellness Program? (check one)

\begin{tabular}{cccc} 
Very Dissatisfied & Dissatisfied & Satisfied & Very Satisfied \\
\hline$\square$ & $\square$ & $\square$ & $\square$
\end{tabular}

11. What do you like most about participating in the Health and Wellness Program?

12. What do you dislike most about participating in the Health and Wellness Program? 
13. What suggestions do you have for improving the Health and Wellness Program?

14. Please provide any additional comments that you have about Schneider's Health and Wellness Program in the space provided.

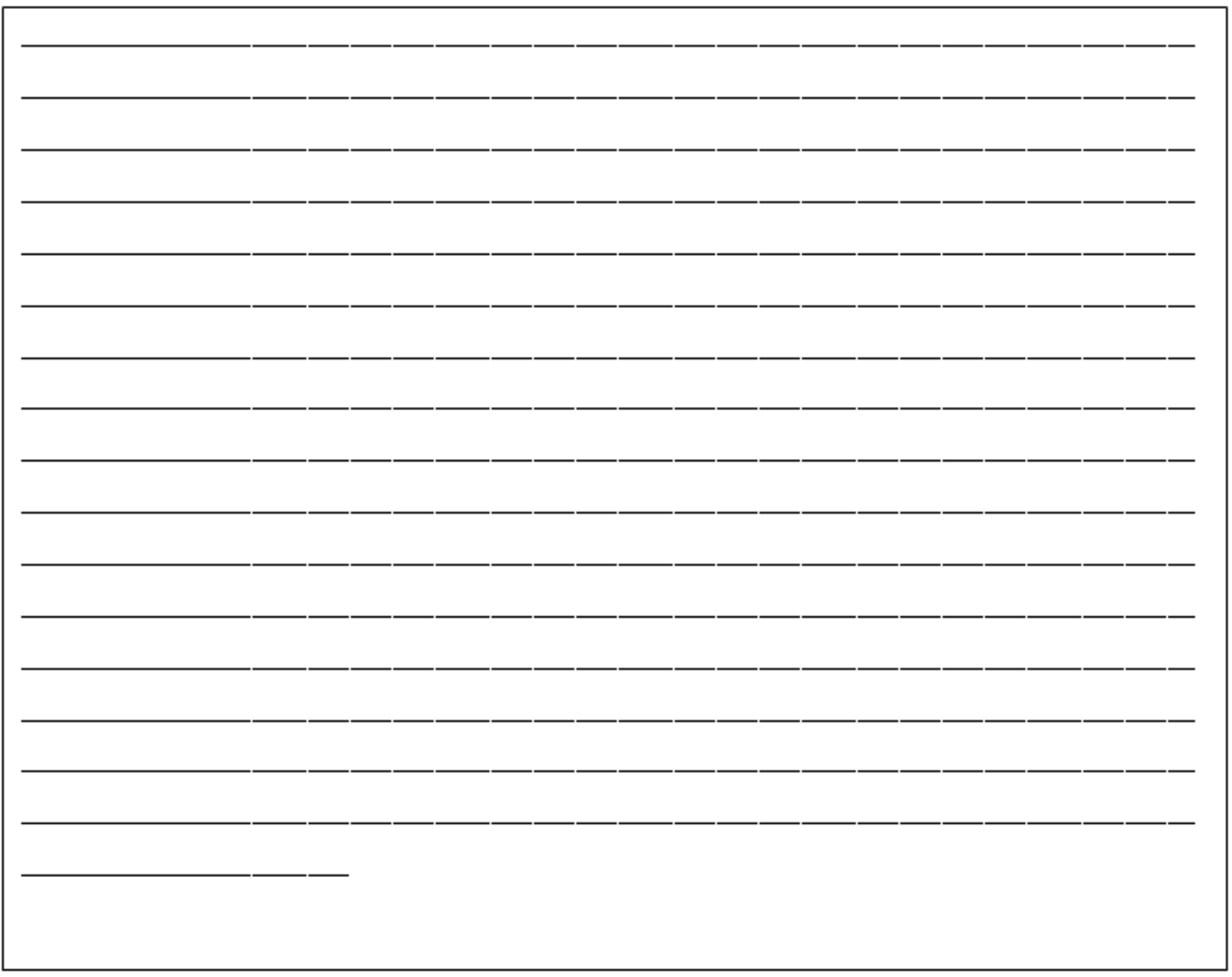




\section{STAFF SURVEY}

Thank you for taking the time to complete this survey. The goal of this survey is to understand how you feel about Schneider's Health and Wellness Program with Atlas Ergonomics. Please be assured that your answers will be kept confidential.

\section{Please select your gender}

$\square$ Male

$\square$ Female

\section{What is your age category?}

Under 25 years

口 25 to 34 years

口 35 to 44 years

$\square 45$ to 54 years

口 55 to 64 years

口 65 to 74 years

$\square 75$ years and older

3. How long have you been working with Schneider's Health and Wellness Program with Atlas?

Less than 6 months

口 6 months to a year

$\square 1$ to 2 years

口 2 to 3 years

口 3 to 4 years

$\square$ Over 4 years

4. How much education do you give Schneider drivers participating in the Health and Wellness Program on the following topics? Please rate the education provided:

\begin{tabular}{|l|r|r|r|r|r|c|}
\hline & $\begin{array}{c}\text { Way too } \\
\text { little }\end{array}$ & $\begin{array}{c}\text { Too } \\
\text { little }\end{array}$ & $\begin{array}{c}\text { About } \\
\text { right }\end{array}$ & $\begin{array}{c}\text { Too } \\
\text { much }\end{array}$ & $\begin{array}{c}\text { Way too } \\
\text { much }\end{array}$ & $\begin{array}{c}\text { I do not educate } \\
\text { drivers on this }\end{array}$ \\
\hline $\begin{array}{l}\text { Nutrition/diet- } \\
\text { general } \\
\text { information }\end{array}$ & $\square$ & $\square$ & $\square$ & $\square$ & $\square$ & $\square$ \\
\hline Exercise-general & $\square$ & $\square$ & $\square$ & $\square$ & $\square$ & $\square$ \\
\hline
\end{tabular}




\begin{tabular}{|l|r|r|r|r|r|r|}
\hline information & & & & & & \\
\hline Weight loss & $\square$ & $\square$ & $\square$ & $\square$ & $\square$ & $\square$ \\
\hline $\begin{array}{l}\text { Eating healthy on } \\
\text { the road }\end{array}$ & $\square$ & $\square$ & $\square$ & $\square$ & $\square$ & $\square$ \\
\hline $\begin{array}{l}\text { Exercising on the } \\
\text { road }\end{array}$ & $\square$ & $\square$ & $\square$ & $\square$ & $\square$ & $\square$ \\
\hline $\begin{array}{l}\text { Hypertension } \\
\text { prevention/control }\end{array}$ & $\square$ & $\square$ & $\square$ & $\square$ & $\square$ & $\square$ \\
\hline $\begin{array}{l}\text { Diabetes } \\
\text { prevention/control }\end{array}$ & $\square$ & $\square$ & $\square$ & $\square$ & $\square$ & $\square$ \\
\hline Surgery & $\square$ & $\square$ & $\square$ & $\square$ & $\square$ & $\square$ \\
\hline Other (please list) & $\square$ & $\square$ & $\square$ & $\square$ & $\square$ & $\square$ \\
\hline
\end{tabular}

5. Do you have suggestions for improving the education Schneider drivers receive as part of the Health and Wellness Program?

$\square$ No

$\square$ Yes (please explain):

6. Please rate the overall adequacy of the health testing/assessments drivers undergo:

adequate

Inadequate (please explain):

\section{Don't Know}

7. Do you have suggestions for improving the health testing/assessments Schneider drivers undergo as part of the Health and Wellness Program?

$\square$ No

Yes (please explain):

8. What do you think works well regarding the Schneider Health and Wellness Program with Atlas? 
9. What do you think could be improved upon regarding the Health and Wellness Program?

10. What suggestions do you have for improving the Health and Wellness Program?

11. Overall, how would you rate Schneider's Health and Wellness Program with Atlas? (check one)

\begin{tabular}{cccc} 
Very Poor & Poor & Good & Very Good \\
\hline$\square$ & $\square$ & $\square$ & $\square$
\end{tabular}

12. Please provide any additional comments that you have about Schneider's Health and Wellness Program in the space provided. 


\section{REFERENCES}

1. $\quad$ Flegal, K.M., et al., Prevalence and trends in obesity among US adults, 1999-2008. Journal of the American Medical Association, 2010. 303(3): p. 235-41.

2. Howard, M.E., et al., Sleepiness, sleep-disordered breathing, and accident risk factors in commercial vehicle drivers. American Journal of Respiratory and Critical Care Medicine, 2004. 170(9): p. 1014-21.

3. Whitfield Jacobson PJ, P.A., Lukaszuk JM, Long-haul truck drivers want healthful meal options at truck-stop restaurants. J Am Diet Assoc., 2007. 107(12): p. 2125-9.

4. Schulte, P.A., et al., Work, obesity, and occupational safety and health. Am J Public Health, 2007. 97(3): p. 428-36.

5. Aldana, S.G. and N.P. Pronk, Health promotion programs, modifiable health risks, and employee absenteeism. J Occup Environ Med, 2001. 43(1): p. 36-46.

6. Schmier, J.K., M.L. Jones, and M.T. Halpern, Cost of obesity in the workplace. Scand J Work Environ Health, 2006. 32(1): p. 5-11.

7. Burton, W.N., et al., The economic costs associated with body mass index in a workplace. J Occup Environ Med, 1998. 40(9): p. 786-92.

8. Anderson, J.E., et al., Obesity is associated with the future risk of heavy truck crashes among newly recruited commercial drivers. Accid Anal Prev, 2012. 49: p. 378-84.

9. Bungum, T., et al., The relationship of body mass index, medical costs, and job absenteeism. Am J Health Behav, 2003. 27(4): p. 456-62.

10. Hours of Service Regulations. 2004.

11. Soderstrom, M.I.E., et al., Exhaustion: Of importance for health and work performance among train drivers? International Journal of Psychology, 2000. 35(3-4): p. 309-309.

12. da Silva-Junior, F., de Pinho, RSN, de Mello, MT, de Bruin, VMS, de Bruin PFC, Risk factors for depression in truck drivers. Social Psychiatry Psychiatric Epidemiology, 2009. 44: p. 125-129.

13. Lyznicki, J.M., et al., Sleepiness, driving, and motor vehicle crashes. Council on Scientific Affairs, American Medical Association. JAMA, 1998. 279(23): p. 1908-13.

14. Dinges, D.F., An overview of sleepiness and accidents. J Sleep Res, 1995. 4(S2): p. 4-14.

15. Statistics, B.o.L., Nonfatal occupational injuries and illnesses requiring days away from work. . 2009.

16. Statistics, B.o.L., Fatal occupational injuries by occupation and event or exposure. 2009.

17. Harshman, R.S., et al., Impact of a hypertension management/health promotion program on commercial driver's license employees of a self-insured utility company. Journal of Occupational and Environmental Medicine, 2008. 50(3): p. 359-65.

18. Pi-Sunyer, X., Becker, D.M., Bouchard, C., et. al., Clinical guidelines on the identification, evaluation, and treatment of overweight and obesity in adults. 1998, (L. National Heart, and Blood Institute, Trans.): National Institutes of Health.

19. Heron, M., Hoyert, D. L., Murphy, S. L., Xu, J., Kochanek, K. D., \& Tejada-Vera, B., Deaths: Final data for 2006. . 2009, Natl Vital Stat Rep. p. 1-134.

20. Administration, F.M.C.S., Fmcsa expert panel recommendations: Cardiovascular disease and commercial motor vehicle driver safety. . 2007, Federal Motor Carrier Safety Administration: Washington, D.C.

21. Prochaska, J.O., et al., Stages of change and decisional balance for 12 problem behaviors. Health Psychol, 1994. 13(1): p. 39-46. 
22. Johnson, S.S., et al., Transtheoretical model-based multiple behavior intervention for weight management: effectiveness on a population basis. Prev Med, 2008. 46(3): p. 23846.

23. Solutions, O.C., QuitPower Advanced Tobacco Cessation. 2011. 